\title{
ANÁLISIS DE CONTENIDO DE LAS WEBS DE LAS BODEGAS ARAGONESAS COMO HERRAMIENTA DE MARKETING ${ }^{1}$
}

\author{
Mercedes Marzo-Navarro* \\ Universidad de Zaragoza \\ https://orcid.org/0000-0002-9628-5738 \\ Marta Pedraja-Iglesias \\ Universidad de Zaragoza \\ https://orcid.org/0000-0002-2551-5364
}

\section{RESUMEN}

Las webs constituyen una herramienta para que las bodegas puedan alcanzar más fácilmente sus objetivos de negocio. Se analiza si las bodegas utilizan esta herramienta y, en caso afirmativo, se investiga el papel que desempeña en su estrategia de marketing teniendo en cuenta las orientaciones establecidas en la literatura. Se observa una alta tasa de existencia de webs, pero el análisis de contenido muestra que la orientación más básica (proporcionar información) es la predominante; seguido de la comunicación interactiva, siendo la orientación transaccional la que muestra una escasa presencia.

Palabras clave: Marketing online; webs; análisis de contenido; orientación a la información; orientación a la comunicación; orientación transaccional; integración interna; integración externa; bodegas; Aragón (España).

\section{Web pages as a marketing tool: content analysis related to Aragonese wineries}

\section{ABSTRACT}

Websites are a tool for wineries to achieve their business objectives more easily. It is analysed whether the wineries use this tool and, if so, the role it plays in their marketing strategy is investigated, taking into account the guidelines established in the literature. There

Fecha de recepción: 6 de marzo de 2019

Fecha de aceptación: 31 de octubre de 2019

1 Este trabajo ha sido apoyado por Fondos Europeos de Desarrollo Regional y la Diputación General de Aragón (Grupo de Investigación S42_17R: CREVALOR.

* Facultad de Economía y Empresa. Universidad de Zaragoza. Gran Vía, 2. 50005 Zaragoza (España). E-mail: mmarzo@unizar.es,mpedraja@unizar.es 
is a high rate of websites, but content analysis shows that the most basic orientation (providing information) is predominant; followed by interactive communication, with transactional orientation showing little presence.

Keywords: Online marketing; web pages; content analysis; information orientation; communication orientation; transactional orientation; internal integration; external integration; wineries; Aragón (Spain).

\section{INTRODUCCIÓN}

Las últimas décadas se han caracterizado por un rápido desarrollo de las tecnologías de la información (TIC), entre las que destaca Internet. Internet ha modificado la forma de realizar las transacciones, ofreciendo distintos tipos de información e incrementando la utilidad y la eficiencia de los sistemas de distribución (Kim, Kim y Han, 2007). El gran crecimiento del uso de Internet y del comercio electrónico ha dado lugar al desarrollo de distintos modelos que permiten comprender mejor los negocios en este nuevo contexto (Davidson, 2002; Goodman, 2003; Rao, Metts y Mora, 2003; Sellitto y McKenzie, 2005; Zhu, Basil y Gordon, 2009). Así, Internet se ha convertido en una tecnología vital para el desarrollo de los negocios, ya que proporciona un potente conjunto de herramientas que pueden ser utilizadas para mejorar muchas de las actividades desarrolladas, como la distribución y comunicación del producto, la interacción con los proveedores y el servicio post-venta al cliente (Campubrí y Galí, 2015; Turban et al., 2002). Internet proporciona a las empresas la oportunidad de mejorar tanto su eficiencia como su productividad, mejorando así sus beneficios económicos (Alonso, 2013).

Las TIC están muy presentes en la vida cotidiana de los individuos, por lo que la presentación de la empresa y su producto en Internet es vital para el éxito del negocio. Las páginas web de las empresas se han convertido en una herramienta fundamental en sus estrategias de marketing, constituyendo parte de la imagen de marca tanto de la organización como de su producto (Bruwer y Good, 2005). Muchos consumidores buscan las webs para poder familiarizarse con la empresa y con sus productos, y obtener así información que les facilite su decisión de compra. Por tanto, entre las principales aportaciones que las webs realizan a la estrategia de negocio destacan proporcionar información a los consumidores, proporcionar la posibilidad de desarrollar el comercio electrónico, y desarrollar relaciones interactivas entre las empresas y consumidores (Ferreira y Ferreira, 2013; Law, Qi y Buhalis, 2010; Notta y Vlachvei, 2013). En resumen, las webs suponen una oportunidad excepcional para la construcción de relaciones empresa-cliente a través de su personalización e interactividad (Hu, Han, Jang y Bai, 2005). Esto es especialmente importante para las pequeñas y medianas empresas (PYMEs), ya que Internet les proporciona oportunidades a las que de otra manera no tendrían acceso (Gilmore, Gallagher y Henry, 2007).

En general, la industria del vino está integrada mayoritariamente PYMEs cuyos recursos, tanto económicos como humanos, son limitados. En el caso español, los últimos datos proporcionados por el Observatorio Español del Mercado del Vino (OeMv), correspondientes a 2018, indican que el 56,5\% de las bodegas tienen entre 0 y 2 asalariados. A este 
pequeño tamaño se le debe unir el hecho que la actual industria del vino se caracteriza por una competencia muy intensa, tanto en mercados nacionales como internacionales. En este contexto, las pequeñas y medianas bodegas se enfrentan a dificultades entre las que destaca encontrar distribuidores de sus vinos que les proporcionen un adecuado lugar de venta (Ferreira y Ferreira, 2013) y, por lo tanto, la posibilidad de competir. En este contexto, Internet emerge como una herramienta que puede ayudar a las bodegas a superar obstáculos y mejorar así sus negocios. Además, las características intrínsecas del vino, el hecho de ser un producto de experiencia y muy diferenciado facilitan que el uso de Internet pueda incrementar significativamente su valor percibido (Giraud-Héraud, Soler y Tanguy, 2001). El marketing del vino es intensivo en información, tanto sobre los aspectos tangibles del producto como sobre los símbolos, tradiciones, cultura, turismo y gastronomía (Stricker, Mueller y Sumner, 2007). La decisión de compra y, por lo tanto, las ventas de vino están muy influenciadas por la información que haya recopilado el consumidor antes de su compra (Mills, Pitt y Sattari, 2012). Esto hace que las webs de las bodegas se convierten en una parte muy importante de su estrategia global de marketing a través de la información que proporcionan (Iaia, Scorrano, Fait y Cavallo, 2017; Yuan, Morrison, Linton, Feng y Jeon, 2004). Al igual que otras industrias, la creciente tendencia de los consumidores a utilizar Internet como un medio para encontrar información sobre las marcas y productos vitivinícolas antes de tomar una decisión de compra también ha provocado cambios en las estrategias de comunicación de las empresas de este sector. Además, Internet permite desarrollar una estrategia de marketing relacional, ya que posee gran interactividad, transfiere eficientemente la información, posibilita la individualización de la comunicación, así como la integración de la comunicación y de las transacciones al ofrecer la posibilidad de compra (Bauer, Grether y Leach, 2002). Por tanto, la web de la bodega resultará determinante para poder ajustarse a las necesidades y deseos del mercado.

El principal objetivo de este estudio se centra en evaluar las webs existentes en una de las principales zonas productoras de vino de calidad de España, Aragón. En Aragón existen cuatro Denominaciones de Origen (D.O.) oficialmente reconocidas, lo que pone de manifiesto su potencial de negocio tanto en el mercado nacional como internacional. Además, las zonas geográficas en las que se ubican las D.O. presentan distintas características, tanto geográficas como de desarrollo socioeconómico. Sin embargo, en todas ellas predominan las pequeñas y medianas bodegas. Por tanto, el uso de Internet a través de una herramienta como las páginas webs les puede permitir acceder, en mejores condiciones, a nuevas oportunidades de negocio. En este contexto, el principal objetivo del trabajo es determinar si las bodegas existentes emplean Internet, y más concretamente las páginas web, dentro de su estrategia de negocio. Una vez determinada la disponibilidad de webs asociadas a las bodegas, se pretende, en segundo lugar, determinar el grado de desarrollo de dichas webs, a través del análisis de su contenido, para poder detectar los principales objetivos a alcanzar relacionados con la creación de vínculos con los consumidores. Es decir, se analiza si están diseñadas para ofrecer únicamente información sobre sus empresas y productos, si permiten la realización de transacciones, si proporcionan los medios para una comunicación interactiva con sus clientes o si ponen de manifiesto una orientación de la bodega en la cual se integran diversas redes de negocio a disposición del consumidor. Para ello, tras esta introducción, se procede a analizar el papel de las webs 
dentro de la estrategia de marketing online de las bodegas, así como las principales categorías de webs las cuales reflejan las orientaciones específicas de marketing online que pretenden alcanzar determinados objetivos empresariales. Tras ello, se procede a analizar empíricamente la situación de las webs de las bodegas analizadas, para finalmente poder realizar una serie de recomendaciones orientadas a mejorar la gestión de sus negocios.

\section{LAS WEBS COMO HERRAMIENTA DE MARKETING}

La importancia de Internet para el desarrollo de negocio de las bodegas se manifiesta a través del creciente número de estudios existentes al respecto (Notta y Vlachvei, 2013). Los objetivos de investigación son diversos, aunque se detectan dos líneas principales. Por un lado, destacan los estudios centrados en identificar los beneficios asociados a la adopción de Internet por las bodegas (Quinton y Harridge-March, 2006; Sellitto y Martin, 2003; Stricker, Mueller y Sumner, 2007); y, por otro, aquellos centrados en determinar las características técnicas que deben estar presentes en la web. Así, diversos estudios (Everard y Galleta, 2006; Lynch y Horton, 2002; Nowak y Newton, 2008) ponen de manifiesto el efecto negativo que tiene una web mal diseñada o con mala información sobre las percepciones de los consumidores, pudiéndose incluso generar una imagen de mala calidad de los vinos de la bodega.

En cualquier caso, está aceptado que, como en cualquier otro negocio, la página web de una bodega debe estar orientada hacia el logro de determinados objetivos de marketing, entre los que se encuentran proporcionar información sobre el producto, proporcionar un canal seguro para el comercio electrónico, establecer y mantener relaciones con los clientes o atraer visitantes a la bodega (Ferreira y Ferreira, 2013). La web se ha convertido en una pieza fundamental en el desarrollo y gestión de las actividades de marketing, que se caracterizan por la creatividad, el dinamismo y el contacto directo con el cliente final (Quinton y Harridge-March, 2006).

En la actualidad está claro el importante papel que, en la mayoría de los sectores, desempeña Internet como un canal de venta, así como fuente de información sobre los productos. Las bodegas se están enfrentando a una competencia cada vez más intensa, tanto en sus mercados nacionales como internacionales. Pero, como ya se ha destacado, las pequeñas y medianas bodegas suelen tener importantes dificultades para encontrar distribuidores que les proporcionen un lugar de venta adecuado para sus vinos (Ferreira y Ferreira, 2013) y poder así competir en los distintos mercados. En este sector, las principales formas a través de la cuales un cliente puede comprar vino en Internet son (Sellito, Wenn y Burges, 2003): i) a través de un distribuidor general que vende el vino como parte de una cartera más amplia de productos; ii) a partir de un distribuidor de vinos especializado; y, iii) directamente desde el fabricante, es decir, a través de la web propia de la bodega. Los dos primeros medios presentan como principal problema para las bodegas que los clientes potenciales los pueden utilizar para realizar webrooming. Por lo tanto, pueden acceder a información sobre sus vinos, pero también sobre los de la competencia modificando así la intención inicial de compra. En España, dentro de los distribuidores especializados, destaca Uvinum (http://www.uvinum. es/), portal líder en venta online de vino (más de medio millón de botellas anuales), con un catálogo de más de 65.000 productos, 115.000 clientes y más de 14 países donde envía sus 
productos. En este portal se realizan recomendaciones de vinos, comparaciones, ofertas, etc. Aunque estar presente en canales generales y especializados resulte necesario, la web propia de cada bodega cobra cada vez más importancia como canal de venta. Así, en 2018, el 51\% de las bodegas españolas contaba con una web en la cual, entre los objetivos que se persiguen se encontraba el desarrollo del comercio electrónico, ya que disponen de tienda online para vender sus vinos (Raw, 2018). Por tanto, entre otros objetivos, las bodegas pueden utilizar la web como una herramienta de marketing que les permite superar las limitaciones de los canales de distribución existentes y expandir así sus ventas directas y al por menor. Para ello, se requiere que la bodega asigne el tiempo y los recursos suficientes para gestionar las órdenes de venta, las preguntas de los clientes, mantener actualizada la web, indicar los precios de sus productos, la disponibilidad de existencias, y las descripciones de los productos. Destacar que esta compra online ha sido estudiada desde múltiples perspectivas en la literatura especializada, desde los modelos de negocio online en la industria del vino (Gebauer y Ginsburg, 2003) hasta las motivaciones y comportamientos de los compradores de vino online (Bruwer y Wood, 2005).

Por otra parte, la web puede corresponderse con el objetivo de desarrollar una labor educacional si se diseña como una fuente de información que nutra las relaciones con los clientes (Ferreira y Ferreira, 2013). Los consumidores prefieren las webs que les proporcionan herramientas efectivas para obtener información y mejorar su conocimiento sobre los productos existentes (Simeon y Sayeed, 2011). Entre los diversos inputs informativos que puede incluir ocupan un lugar destacado la que se proporciona sobre la historia de la bodega, así como descripciones detalladas sobre los procesos de elaboración del vino, ya que influyen positivamente en la selección y adquisición de este producto (Mueller, Sidscz, Francis y Lockshin., 2010). La inclusión de características educativas en la web puede aumentar el interés por el producto vino, dando lugar a una mayor lealtad hacia la bodega y sus productos (Beverland et al., 1998). Este interés e implicación con el producto vino constituye uno de los principales predictores de la venta, así como de la probabilidad de realizar distintas actividades relacionadas con el vino y sus bodegas (Marzo-Navarro y Pedraja-Iglesias, 2012). Por tanto, educar al cliente a través de la información proporcionada en la web tiene el potencial de retener y ampliar la base de clientes existente (Hall, 1996).

Junto a lo anteriormente destacado, las relaciones con los clientes se pueden también mejorar a través de la web, haciendo que los clientes puedan interactuar tanto con la bodega como con otros clientes. A través de estas interactuaciones las bodegas pueden gestionar tanto su imagen de marca como otros aspectos intangibles de su negocio. Así, las bodegas que gestionan adecuadamente las relaciones online con sus clientes pueden mejorar sus cuotas de mercado, manteniendo e incrementado clientes (Hall y Winchester, 2000; O’Neill, Palmer y Charters, 2002).

Pero, pese a que las webs se diseñen para poder alcanzar estos objetivos, son pocas las que obtienen un retorno adecuado (Ness, 2006). La web puede constituir el primer, y a veces único, contacto que un cliente potencial puede tener con la bodega. Estos clientes poseen altas expectativas sobre la calidad de las webs (Velikova, Wilcox y Dodd, 2011) y, sin embargo, muchas de las webs de las bodegas son simples folletos electrónicos y no herramientas de marketing dinámicas y eficientes (Ferreira y Ferreira, 2013). La usabilidad 
de la web se evalúa a través de su categoría técnica, su diseño y su contenido (Bernet y Stricker, 2003; Davidson, 2004; 2008; Stevens y Burns, 2005).

Pero la mayoría de los consumidores carecen de conocimientos previos de programación, por lo que sólo pueden evaluar y tener en cuenta el diseño y el contenido de la web. Así, las impresiones iniciales que, sobre la web, tenga el cliente son críticas, por lo que la bodega debe esforzarse por desarrollar y mantener una web atractiva, actualizada y fácil de usar. Si los consumidores no son capaces de encontrar rápidamente la información necesaria probablemente abandonen el sitio web (Forrester Research, 2009). Además de la rapidez, el diseño y el contenido del sitio web también afectan a la percepción del consumidor sobre la bodega y sus productos. Los consumidores se forman sus creencias y actitudes sobre la empresa y sus productos atendiendo a la manera en que éstos se presentan en la web. Una mala actuación de la web se convierte en una de las principales causas de la insatisfacción del cliente, por lo que, si la web no le genera una buena experiencia, no volverá a ella. Esto provoca la pérdida de una venta potencial o de un futuro visitante de la bodega (Belanger et al., 2006; Nielsen, 2000; 2002).

La información relativa a los factores que hacen eficaces las webs de las bodegas es muy importante, especialmente para las pequeñas y medianas bodegas (Johnston, Wade y McClean, 2007; Ness, 2006). Sin embargo, éstas no suelen disponer de los recursos suficientes para contratar a un profesional que les ayude en la creación y gestión de su web (Velikova et al., 2011). Por tanto, si los gestores de las bodegas deciden estar presentes en el medio online, deberán tener en cuenta que hay que dedicar los recursos necesarios para el mantenimiento y actualización de la web de manera que se puedan alcanzar los objetivos establecidos. Los sitios web deben madurar con el tiempo, mejorando su contenido y funcionalidad (Burgess y Cooper, 1999; 2000; Ho, 1997; Timmers, 2000). Esta madurez debería producir un incremento de la satisfacción del cliente con la información proporcionada y las relaciones establecidas y, por tanto, un aumento de las ventas resultantes y de los resultados de las redes de negocio. En caso contrario, la web puede generar efectos negativos como, por ejemplo, una mala imagen de la bodega.

\section{PRINCIPALES ORIENTACIONES DE LAS WEBS}

Los objetivos organizacionales que se persiguen a través del uso de una web son básicamente dos, transaccionales y de información (Bruwer y Wood, 2005), por lo que su diseño y contenido debe estar en consonancia con dichos objetivos. Pero también se puede considerar una forma intermedia, denominada interactiva que, aunque no permite la compra directa online, sí que proporciona herramientas para que la empresa interrelacione con los clientes, y éstos entre ellos (Guräu y Dusquenois, 2011; Sellito y Martin, 2003). Estas tres categorías de webs se corresponden con las tres orientaciones específicas de marketing online:

- Orientación a la información: la web sólo se utiliza para dar información sobre la bodega, el vino, la ubicación de la empresa, y los canales de distribución. Aunque se proporciona la dirección postal y el número de teléfono de la bodega, no existe una dirección de correo electrónico para poder generar una comunicación directa 
interactiva bodega-cliente. Esta web era la predominante al inicio de internet, pero hoy en día debería ser una excepción.

- Enfoque comunicación interactiva: la web mantiene su función informativa sobre la bodega, sus productos, ubicación y distribución, pero también ofrece herramientas para una comunicación interactiva que permita al cliente iniciar un diálogo directo con la bodega y/o con otros clientes. Esta herramienta de comunicación suele ser el correo electrónico, pero algunas empresas crean comunidades basadas en un blog o foro de discusión. En este enfoque interactivo no son sólo los clientes quienes pueden iniciar la comunicación. La bodega también puede invitar a sus clientes a que se registren y proporcionen información sobre su perfil demográfico, sus necesidades específicas en términos del tipo de producto, y sus intereses particulares relacionados con el vino. Esta información se puede utilizar para desarrollar una base de datos, que permita desarrollar relaciones personalizadas con cada cliente (ofertas especiales, información y/o noticias). Sin embargo, aunque esta web proporciona información como si fuera un catálogo de productos con sus precios, no permite pedidos online ni lógicamente su pago. Puede proporcionar información sobre minoristas o webs especializadas donde se venden sus vinos para que el consumidor realice allí la compra.

- Orientación Transaccional: estas webs son más complejas en términos de funcionalidad. A la información y a la comunicación de las orientaciones previas se le suma la facilidad para comprar y pagar online los productos. Esta función transaccional implica que se realice una transferencia segura de información personal y financiera, así como la presentación de información clara y detallada sobre las condiciones de venta y devolución de productos. Estas webs suelen proporcionar información detallada sobre los productos en venta, para facilitar la elección de los consumidores y reducir su percepción de riesgo. El catálogo de los productos es complejo, con una detallada presentación en texto, imágenes y, a veces, comentarios y recomendaciones de clientes reales.

A estas tres orientaciones tradicionales, autores como Rao, Metts y Mora (2003) y Zhu, Basil y Gordon (2009) añaden una cuarta en el proceso de desarrollo del comercio electrónico por parte de las empresas. Esta cuarta orientación fue denominada Integración de la empresa.

- Integración de la Empresa: esta orientación pretende la integración del Customer Relationship Management, del Value Chain Management, y del Supply Chain Management. Una de las principales barreras que tienen las empresas para llegar a esta orientación se centra en la gestión de las relaciones con los socios externos. Para poder generar valor añadido, muchas empresas necesitan establecer redes de negocio e integrarse con otras empresas, con proveedores y con otras industrias de apoyo. Estos negocios no tienen por qué estar físicamente cercanos, ya que internet permite la colaboración a través de las redes virtuales. Esta integración se puede realizar tanto interna como externamente. La Integración Interna se produce cuando la empresa expande sus ofertas para poder satisfacer una mayor variedad de necesidades de los 
clientes. En el caso de las bodegas esto se refleja en la oferta, en sus propias webs, de productos periféricos a la venta de vino. Este sería el caso de, por ejemplo, una bodega que venda alimentos para acompañar a sus catas de vinos, o que alquile sus salas para reuniones o que permita el acceso a sus museos o centros de documentación. De esta manera, se ofrecen distintas categorías de productos y se facilita su compra en una sola ocasión, lo que ahorra tiempo a los consumidores (McDonald, 1994; Messinger y Narasimhan 1997). Por su parte, la Integración Externa se establece con empresas con las cuales se intentan mejorar sus oportunidades de negocio y el servicio al cliente mediante el acceso a los recursos que van más allá de las propias ofertas de la bodega. Este sería el caso de bodegas que ofrecen servicios de alojamiento o restauración a sus clientes en hoteles o restaurantes de la zona. Esta integración externa de la empresa puede dar lugar al turismo del vino, proporcionando oportunidades de desarrollo para toda la zona. Para poder alcanzar este objetivo, la web debe generar curiosidad e interés como atracción turística, no sólo de la bodega, sino de la zona en la que está inmersa. La información que se proporcione sobre las atracciones turísticas y los eventos de la región resultan críticos en la estrategia del turismo del vino. Para que este tipo de turismo tenga éxito, las bodegas y los viñedos no pueden constituir la única atracción de la zona. Se deben incluir atracciones adicionales, como alta cocina, experiencias culturales y buenas opciones de alojamiento para conseguir el éxito del destino (Beames, 2003; Getz et al., 2008; Marzo-Navarro y Pedraja-Iglesias, 2009). Algunas bodegas son el elemento turístico principal de una región mientras que otras son secundarias al estar cerca de un destino turístico importante, lo que le proporciona una ventaja competitiva. En cualquier caso, las webs pueden emplearse para promocionar conjuntamente a la región, sirviendo así de plataforma para desarrollar alianzas estratégicas. En este contexto, internet se convierte en una herramienta básica tanto para la gestión como para la promoción de este tipo de actividad turística, convirtiéndose en una potente herramienta para difundir información sobre el producto turístico, los destinos y el turismo del vino (Amaro, Barroco y Antunes, 2010). Una percepción positiva de la bodega, sus productos, la zona y de las actividades ofertadas generada a través de la web puede provocar una primera visita o una repetición dando así lugar a la oportunidad de negocio.

Por tanto, el análisis de contenido de sus webs pondrá de manifiesto los objetivos perseguidos por las bodegas $\mathrm{y}$, por tanto, la orientación de marketing online seguida en sus estrategias.

\section{METODOLOGíA}

\subsection{Webs Analizadas: Bodegas Aragonesas}

La información analizada proviene del análisis de las webs de las bodegas integrantes de las cuatro D.O. existentes en Aragón: Calatayud, Campo de Borja, Cariñena y Somontano. Se optó por esta zona debido a las siguientes razones: i) es una zona con gran tradición vinícola en España, como se pone de manifiesto en el hecho que la D.O. Cariñena date de 1932; ii) conviven cuatro D.O. situadas en zonas geográficas con diferentes características, 
lo que podría influir en la orientación de sus webs en caso de tenerlas; iii) predominan las pequeñas y medianas bodegas, en torno al 80\% (Pedraja-Iglesias y Marzo-Navarro, 2014), por lo que el desarrollo de sus webs les brinda la oportunidad de acceder a nuevas oportunidades de negocio; y, iv) el número total de bodegas con D.O. existentes no es excesivamente elevado lo que facilita la aplicación del esquema propuesto para el análisis de contenido. Destacar que sólo se analizan las bodegas pertenecientes a las D.O. ya que, dada la legislación vigente, éstas sirven para designar y proteger un producto perteneciente a una zona determinada, implicando además tradiciones, costumbres, mitos, leyendas y la historia de esos lugares, lo que les concede un valor añadido que mejora su competitividad y facilita la formación de redes de negocio.

\subsection{Proceso de Evaluación de las Webs: Análisis de Contenido}

Para elaborar la base de datos que recogiese el listado de todas las bodegas existentes, se consultaron las páginas webs de sus respectivos Consejos Reguladores (www.docalatayud.com; www.campodeborja.com; www.docarinena.es; www.dosomontano.com). La recogida de la información se realizó en enero de 2017, obteniéndose información sobre el total de la población objeto de estudio. Así, se procedió a determinar si las bodegas integrantes de las cuatro D.O. poseían o no página web, pudiendo así calcular la tasa penetración de esta herramienta.

Posteriormente, si la bodega tenía web se procedió, a realizar un análisis de contenido. El análisis de contenido es un método de investigación muy utilizado para la realización de un examen objetivo, sistemático y cuantitativo del contenido de una determinada información (Berelson, 1952). Concretamente, se realiza un análisis de contenido cuantitativo, técnica empleada para realizar inferencias válidas y fiables de los datos a su contexto (Krippendorff, 2012). Los criterios de evaluación son los mostrados en el Cuadro 1, los cuales han sido propuestos por los autores del trabajo a partir de la revisión de la literatura especializada.

Así, para analizar la orientación presente en las webs de las bodegas, se proponen las dimensiones, y sus respectivos criterios de evaluación, mostradas en el Cuadro 1, las cuales se basan en el esquema propuesto por Hasmin, Murphy y Law (2007). Estos autores realizaron un meta análisis de los principales estudios sobre webs de servicios turísticos y sobre las webs de las bodegas (Davidson, 2008; Gurau y Duquesnois, 2011; Jankulovic, Stamatovic y Covic, 2013; Murphy, Ho y Chan, 2005; Notta y Vlachvei, 2013; Sellito, 2005; Sellito, Wenn y Burgess, 2003; Velikova, Wilcox y Dodd, 2011).

La primera dimensión "Información y Procesos" recoge fundamentalmente la orientación a la información, así como la orientación transaccional. Comprende la información de contacto de la empresa, la información general de la misma y de sus productos, así como la posibilidad de realizar su compra, informando del proceso a seguir. Por tanto, incluye todo lo necesario para que el cliente contacte con la empresa, obtenga información de la misma, y adquiera sus bienes y servicios (Schegg, Steiner, Frey y Murphy, 2002).

La dimensión "Valor Agregado" incluye la información que permite detectar la integración, tanto interna como externa, de la bodega. Por tanto, se engloban los elementos referidos a otros bienes y servicios ofertados en la propia bodega, complementarios al producto principal vino. Esto representa la orientación a la integración interna de la bodega. Además, se recogen los elementos indicativos de la integración externa, esto es, de la existencia 


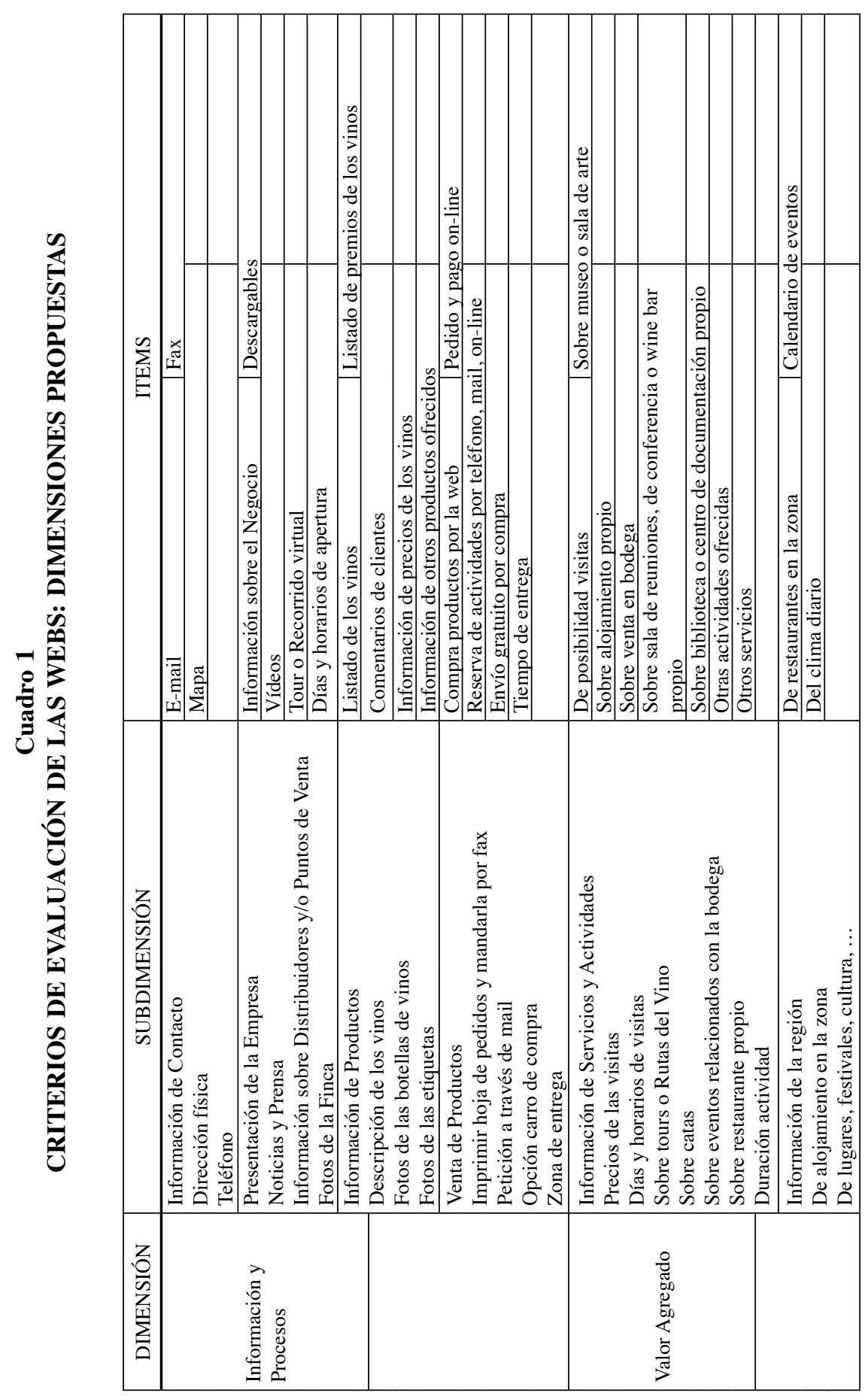




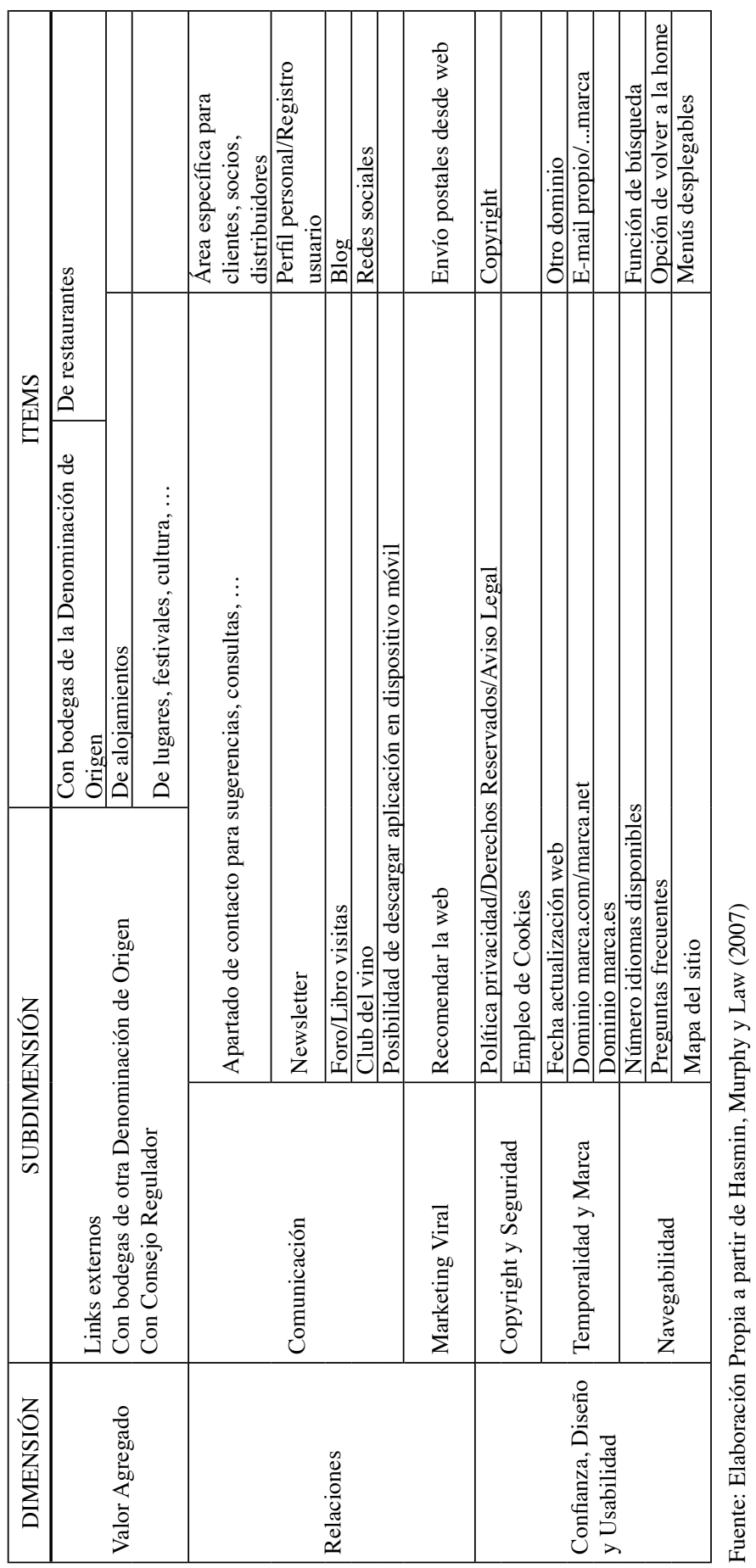


de redes de negocio con otras empresas (por ejemplo, restaurantes, alojamientos u otras bodegas). Así, se analiza la presencia de la información adicional que se le brinda al cliente con el objetivo de generar una oferta turística completa, mejorando la experiencia del viaje (Mitchell y Hall, 2004).

En la dimensión "Relaciones" se agrupan los elementos correspondientes a una comunicación interactiva bodega-cliente y cliente-cliente (Murphy, Ho y Chan, 2005). Comprende las herramientas de marketing relacional empleadas por la bodega para lograr la comunicación y la interacción con el cliente y la personalización de servicios, así como algunas herramientas de marketing viral que pone a disposición del cliente para que comparta sus contactos.

La dimensión "Confianza, Diseño y Usabilidad" está muy relacionada con la dimensión anterior, ya que destaca el rol de la confianza en la creación y construcción de relaciones exitosas con los clientes (Bauer, Grether y Leach, 2002; Wang, Head y Archer, 2000). Los links externos, el copyright y fecha de última actualización incentivan la confianza en el sitio web (Nielsen, 2000), y la marca en el dominio (ejemplo marca.com o marca.es) ayuda a construir valor de marca y aportar confianza (Hanson, 2000; Murphy, Raffa y Mizerski, 2003). Elementos como la seguridad, la credibilidad y la continuidad aumentan la confianza en la empresa y fomentan la lealtad del cliente (Schegg, Steiner, Frey y Murphy, 2002). Además, se recogen los aspectos relacionados con la navegabilidad de la web. No tiene sentido proporcionar mucha información si luego el usuario no puede encontrarla fácilmente (Murphy, Ho y Chan, 2005). La navegabilidad de la web se relaciona directamente con las actitudes positivas hacia el sitio y hacia la marca (Bellman y Rossittier, 2004).

Para garantizar la objetividad del análisis de contenido, todos los criterios mostrados en el Cuadro 1 fueron medidos de manera dicotómica "Sí/No": "Sî" indica la presencia del contenido y "No" su ausencia. Además, para evaluar el nivel global de la información, éste fue evaluado a través de porcentajes $\left(\mathrm{N}^{\mathrm{o}}\right.$ de veces presente el criterio/Total de webs evaluadas). Finalmente, para reducir los sesgos en el proceso de evaluación fueron 2 las personas entrenadas para realizar la codificación de la información de las webs. Este procedimiento ha sido el seguido en investigaciones similares (Ahrens y Coyle, 2011; Kim y Kuljis, 2010; Kim, Yuan, Goh y Antun, 2009; Salleha, Hasmina y Murphya, 2015).

Tras realizar el análisis de contenido se procede a realizar un análisis Clúster con el objetivo de determinar si existen grupos diferenciados de webs en función de su orientación y, por tanto, de su principal objetivo de negocio.

\subsection{Análisis y Resultados}

En primer lugar, se determinó si las bodegas analizadas usaban la web como herramienta dentro de la estrategia de marketing. En la Tabla 1 se observa como la tasa de penetración de las webs es relativamente alta, ya que el 71,71\% del total de las bodegas posee página web en funcionamiento. Se observa que dicha tasa varía atendiendo a la D.O a la que pertenece la bodega, lo cual puede constituir un indicador de la orientación de la web como herramienta de desarrollo de negocio en cada una de las zonas productoras. Así, se observa que las bodegas del Somontano son las que muestran una mayor presencia de webs $(90,32 \%)$, seguidas por las de Calatayud (87,5\%). Las bodegas de Campo de Borja y Cariñena presentan tasas bajas, en torno al $55 \%$. 
Tabla 1

TASA DE PENETRACIÓN DE LAS WEBS EN LAS BODEGAS

\begin{tabular}{|c|c|c|c|c|c|c|c|c|c|c|}
\cline { 2 - 11 } \multicolumn{1}{c|}{} & \multicolumn{2}{c|}{ Calatayud } & \multicolumn{2}{c|}{ Campo Borja } & \multicolumn{2}{c|}{ Cariñena } & \multicolumn{2}{c|}{ Somontano } & \multicolumn{2}{c|}{ Aragón } \\
\cline { 2 - 11 } & $\mathrm{N}$ & $\%$ & $\mathrm{~N}$ & $\%$ & $\mathrm{~N}$ & $\%$ & $\mathrm{~N}$ & $\%$ & $\mathrm{~N}$ & $\%$ \\
\hline $\begin{array}{c}\text { Posee Web } \\
(\mathrm{S} 1 \text { ) }\end{array}$ & 14 & $87,5 \%$ & 10 & $55,55 \%$ & 20 & $54,55 \%$ & 27 & $90,32 \%$ & 71 & $71,71 \%$ \\
\hline $\begin{array}{c}\text { Posee Web } \\
\text { (No) }\end{array}$ & 2 & $12,5 \%$ & 8 & $44,45 \%$ & 15 & $45,45 \%$ & 3 & $9,68 \%$ & 28 & $28,28 \%$ \\
\hline Total & \multicolumn{2}{|c|}{16} & \multicolumn{2}{c|}{18} & \multicolumn{2}{c|}{35} & \multicolumn{2}{c|}{30} & \multicolumn{2}{c|}{99} \\
\hline
\end{tabular}

\subsubsection{Análisis de contenido}

La presencia de cada uno de los criterios de evaluación propuestos en las webs analizadas se muestra en la Tabla 2, evaluándose la presencia de cada uno de ellos atendiendo al número de webs analizadas. Además, dicha información se desagrega atendiendo a las D.O. reconocidas en Aragón.

Tabla 2

PRESENCIA CRITERIOS DE EVALUACIÓN SOBRE EL TOTAL DE WEBS (EN \%)

\begin{tabular}{|c|c|c|c|c|c|c|c|}
\hline Dimensión & Subdimensión & Items & ARAGÓN & Calatayud & $\begin{array}{c}\text { Campo } \\
\text { Borja }\end{array}$ & Cariñena & Somontano \\
\hline \multirow{10}{*}{$\begin{array}{l}\text { Información } \\
\text { y Procesos }\end{array}$} & \multirow{5}{*}{$\begin{array}{l}\text { Información } \\
\text { de Contacto }\end{array}$} & E-mail & 100 & 100 & 100 & 100 & 100 \\
\hline & & $\begin{array}{l}\text { Dirección } \\
\text { física }\end{array}$ & 100 & 100 & 100 & 100 & 100 \\
\hline & & Teléfono & 100 & 100 & 100 & 100 & 100 \\
\hline & & Fax & 77 & 92,86 & 100 & 72,22 & 71,43 \\
\hline & & Mapa & 85,1 & 92,86 & $90,00 \%$ & 72,22 & 100 \\
\hline & \multirow{5}{*}{$\begin{array}{l}\text { Presentación } \\
\text { de la Empresa }\end{array}$} & $\begin{array}{l}\text { Información } \\
\text { sobre el } \\
\text { Negocio }\end{array}$ & 95,9 & 85,71 & 100 & 100 & 96,43 \\
\hline & & $\begin{array}{l}\text { Noticias y } \\
\text { Prensa }\end{array}$ & 54,1 & 50 & 60 & 50 & 53,57 \\
\hline & & \begin{tabular}{|l} 
Información \\
sobre \\
Distribuidores \\
y/o Puntos de \\
Venta
\end{tabular} & 25,7 & 0 & 40 & 22,22 & 35,71 \\
\hline & & $\begin{array}{l}\text { Días y horarios } \\
\text { de apertura }\end{array}$ & 21,6 & 7,14 & 20 & 16,67 & 35,71 \\
\hline & & $\begin{array}{l}\text { Fotos de la } \\
\text { Finca }\end{array}$ & 82,4 & 64,29 & 90 & 94,44 & 82,14 \\
\hline
\end{tabular}




\begin{tabular}{|c|c|c|c|c|c|c|c|}
\hline Dimensión & Subdimensión & Items & ARAGÓN & Calatayud & $\begin{array}{c}\text { Campo } \\
\text { Borja }\end{array}$ & Cariñena & Somontano \\
\hline \multirow{22}{*}{$\begin{array}{l}\text { Información } \\
\text { y Procesos }\end{array}$} & \multirow{12}{*}{$\begin{array}{l}\text { Presentación } \\
\text { de la Empresa }\end{array}$} & $\begin{array}{l}\text { Descargables } \\
\text { (al menos uno) }\end{array}$ & 48,6 & & & & \\
\hline & & Fichas de cata & 29,7 & 50 & 30 & 27,78 & 28,57 \\
\hline & & $\begin{array}{l}\text { Folletos, } \\
\text { catálogos }\end{array}$ & 2,7 & 0 & 0 & 0 & 7,14 \\
\hline & & \begin{tabular}{|l} 
Publicidad, \\
prensa
\end{tabular} & 5,4 & 0 & 0 & 5,56 & 10,71 \\
\hline & & \begin{tabular}{|l} 
Fondo, \\
protector de \\
pantalla \\
\end{tabular} & 0 & 0 & 0 & 0 & 0 \\
\hline & & $\begin{array}{l}\text { Revista, } \\
\text { boletín }\end{array}$ & 0 & 0 & 0 & 0 & 0 \\
\hline & & Fotos & 25,7 & 0 & 30 & 11,11 & 53,57 \\
\hline & & Mapa & 14,9 & 0 & 10 & 0 & 35,71 \\
\hline & & \begin{tabular}{|l|} 
Itinerarios de \\
visitas o rutas \\
\end{tabular} & 1,4 & 0 & 0 & 0 & 3,57 \\
\hline & & Otros & 1,4 & 0 & 0 & 5,56 & 0 \\
\hline & & \begin{tabular}{|l|} 
Vídeos \\
\end{tabular} & 16,2 & 35,71 & 20 & 0 & 14,29 \\
\hline & & \begin{tabular}{|l} 
Tour o \\
Recorrido \\
virtual \\
\end{tabular} & 4,1 & 7,14 & 0 & 0 & 7,14 \\
\hline & \multirow{7}{*}{$\begin{array}{l}\text { Información } \\
\text { de Productos }\end{array}$} & \begin{tabular}{|l|l}
$\begin{array}{l}\text { Listado de los } \\
\text { vinos }\end{array}$ \\
\end{tabular} & 95,9 & 92,86 & 100 & 94,44 & 92,86 \\
\hline & & \begin{tabular}{|l|}
$\begin{array}{l}\text { Descripción de } \\
\text { los vinos }\end{array}$ \\
\end{tabular} & 93,2 & 92,86 & 100 & 88,89 & 89,29 \\
\hline & & \begin{tabular}{|l}
$\begin{array}{l}\text { Fotos de las } \\
\text { botellas de } \\
\text { vinos }\end{array}$ \\
\end{tabular} & 97,3 & 92,86 & 100 & 94,44 & 96,43 \\
\hline & & \begin{tabular}{|l|}
$\begin{array}{l}\text { Fotos de las } \\
\text { etiquetas }\end{array}$ \\
\end{tabular} & 85,1 & 71,43 & 100 & 77,78 & 85,71 \\
\hline & & \begin{tabular}{|l|} 
Listado de \\
premios de los \\
vinos \\
\end{tabular} & 33,8 & 42,86 & 40 & 38,89 & 32,14 \\
\hline & & $\begin{array}{l}\text { Comentarios } \\
\text { de clientes }\end{array}$ & 5,4 & 0 & 10 & 0 & 10,71 \\
\hline & & $\begin{array}{l}\text { Información de } \\
\text { precios de los } \\
\text { vinos }\end{array}$ & 36,5 & 28,57 & 40 & 33,33 & 42,86 \\
\hline & \begin{tabular}{|l|}
$\begin{array}{l}\text { Información } \\
\text { de Productos }\end{array}$ \\
\end{tabular} & $\begin{array}{l}\text { Información de } \\
\text { otros productos } \\
\end{array}$ & 21,6 & 21,43 & 10 & 16,67 & 35,71 \\
\hline & & \begin{tabular}{|l} 
Compra \\
productos por \\
la web
\end{tabular} & 43,2 & 28,57 & 60 & 38,89 & 50 \\
\hline & & $\begin{array}{l}\text { Imprimir hoja } \\
\text { de pedidos y } \\
\text { mandarla por } \\
\text { fax }\end{array}$ & 2,7 & 0 & 0 & 0 & 7,14 \\
\hline
\end{tabular}




\begin{tabular}{|c|c|c|c|c|c|c|c|}
\hline Dimensión & Subdimensión & Items & ARAGÓN & Calatayud & $\begin{array}{c}\text { Campo } \\
\text { Borja }\end{array}$ & Cariñena & Somontano \\
\hline \multirow{7}{*}{$\begin{array}{l}\text { Información } \\
\text { y Procesos }\end{array}$} & \multirow{7}{*}{$\begin{array}{l}\text { Venta de } \\
\text { Productos }\end{array}$} & $\begin{array}{l}\text { Petición a } \\
\text { través de mail }\end{array}$ & 35,1 & 28,57 & 60 & 38,89 & 32,14 \\
\hline & & \begin{tabular}{|l} 
Envío gratuito \\
por compra
\end{tabular} & 14,9 & 0 & 10 & 22,22 & 17,86 \\
\hline & & \begin{tabular}{|l|} 
Carro de \\
compra \\
\end{tabular} & 36,5 & 28,57 & 50 & 33,33 & 39,29 \\
\hline & & \begin{tabular}{|l}
$\begin{array}{l}\text { Tiempo de } \\
\text { entrega }\end{array}$ \\
\end{tabular} & 5,4 & 14,29 & 0 & 5,56 & 3,57 \\
\hline & & \begin{tabular}{|l}
$\begin{array}{l}\text { Zona de } \\
\text { entrega }\end{array}$ \\
\end{tabular} & 17,6 & 7,14 & 20 & 22,22 & 21,43 \\
\hline & & \begin{tabular}{|l} 
Pedido y pago \\
on-line
\end{tabular} & 33,8 & 28,57 & 40 & 33,33 & 35,71 \\
\hline & & $\begin{array}{l}\text { Reserva de } \\
\text { actividades por } \\
\text { teléfono, mail, } \\
\text { on-line } \\
\end{array}$ & 21,6 & 14,29 & 0 & 22,22 & 28,57 \\
\hline \multirow{16}{*}{$\begin{array}{l}\text { Valor } \\
\text { Agregado }\end{array}$} & \multirow{16}{*}{$\begin{array}{l}\text { Información } \\
\text { de Servicios y } \\
\text { Actividades }\end{array}$} & $\begin{array}{l}\text { De posibilidad } \\
\text { visitas }\end{array}$ & 32,4 & 14,29 & 20 & 22,22 & 57,14 \\
\hline & & \begin{tabular}{|l|} 
Precios de las \\
visitas \\
\end{tabular} & & & & & \\
\hline & & \begin{tabular}{|l} 
Gratis \\
\end{tabular} & 5,4 & 0 & 10 & 5,56 & 7,14 \\
\hline & & De 2 a $6 €$ & 6,8 & 0 & 0 & 5,56 & 14,29 \\
\hline & & De 7 a $15 €$ & 8,1 & $14,2 \%$ & 0 & 11,11 & 3,57 \\
\hline & & $16 €$ o más & 0 & 0 & 0 & 0 & 0 \\
\hline & & $\begin{array}{l}\text { Días y horarios } \\
\text { de visitas }\end{array}$ & & & & & \\
\hline & & $\begin{array}{l}\text { Visitas días de } \\
\text { semana }\end{array}$ & 21,6 & 0 & 10 & 16,67 & 42,86 \\
\hline & & $\begin{array}{l}\text { Visitas fin de } \\
\text { semana }\end{array}$ & 21,6 & 0 & 10 & 16,67 & 42,86 \\
\hline & & $\begin{array}{l}\text { Duración de la } \\
\text { actividad }\end{array}$ & 10,8 & 14,29 & 10 & 5,56 & 10,71 \\
\hline & & \begin{tabular}{|l|} 
Sobre tours o \\
Rutas del Vino \\
\end{tabular} & 24,3 & 14,29 & 30 & 11,11 & 35,71 \\
\hline & & \begin{tabular}{|l|} 
Sobre catas \\
\end{tabular} & 20,3 & 7,14 & 0 & 22,22 & 35,71 \\
\hline & & $\begin{array}{l}\begin{array}{l}\text { Sobre eventos } \\
\text { de la bodega }\end{array} \\
\end{array}$ & 18,9 & 7,14 & 0 & 11,11 & 42,86 \\
\hline & & \begin{tabular}{|l} 
Sobre \\
restaurante \\
propio \\
\end{tabular} & 6,8 & 0 & 0 & 11,11 & 10,71 \\
\hline & & $\begin{array}{l}\text { Sobre } \\
\text { alojamiento } \\
\text { propio } \\
\end{array}$ & 2,7 & 0 & 0 & 0 & 7,14 \\
\hline & & $\begin{array}{l}\text { Sobre venta en } \\
\text { bodega }\end{array}$ & 12,2 & 0 & 0 & 11,11 & 25 \\
\hline
\end{tabular}




\begin{tabular}{|c|c|c|c|c|c|c|c|}
\hline Dimensión & Subdimensión & Items & ARAGÓN & Calatayud & $\begin{array}{c}\text { Campo } \\
\text { Borja }\end{array}$ & Cariñena & Somontano \\
\hline \multirow{16}{*}{\begin{tabular}{|l} 
Valor \\
Agregado
\end{tabular}} & \multirow{5}{*}{$\begin{array}{l}\text { Información } \\
\text { de Servicios y } \\
\text { Actividades }\end{array}$} & $\begin{array}{l}\begin{array}{l}\text { Sobre museo o } \\
\text { sala de arte }\end{array} \\
\end{array}$ & 1,4 & 0 & 0 & 0 & 3,57 \\
\hline & & \begin{tabular}{|l|} 
Sobre \\
biblioteca \\
o centro de \\
documentación \\
propio \\
\end{tabular} & 0 & 0 & 0 & 0 & 0 \\
\hline & & \begin{tabular}{|l} 
Sobre sala de \\
reuniones, de \\
conferencia \\
o wine bar \\
propio \\
\end{tabular} & 2,7 & 0 & 0 & 0 & 7,14 \\
\hline & & \begin{tabular}{|l} 
Otras \\
actividades \\
ofrecidas
\end{tabular} & 14,9 & 7,14 & 0 & 5,56 & 35,71 \\
\hline & & \begin{tabular}{|l|} 
Otros servicios \\
\end{tabular} & 13,5 & 7,14 & 0 & 5,56 & 32,14 \\
\hline & \multirow{5}{*}{$\begin{array}{l}\text { Información } \\
\text { de la región }\end{array}$} & $\begin{array}{l}\text { De restaurantes } \\
\text { en la zona }\end{array}$ & 2,7 & 0 & 0 & 0 & 7,14 \\
\hline & & $\begin{array}{l}\text { De alojamiento } \\
\text { en la zona }\end{array}$ & 1,4 & 0 & 10 & 0 & 0 \\
\hline & & \begin{tabular}{|l|} 
De lugares, \\
festivales, \\
cultura, ...
\end{tabular} & 8,1 & 7,14 & 0 & 5,56 & 14,29 \\
\hline & & $\begin{array}{l}\text { Calendario de } \\
\text { eventos }\end{array}$ & 0 & 0 & 0 & 0 & 0 \\
\hline & & $\begin{array}{l}\text { Del clima } \\
\text { diario }\end{array}$ & 0 & 0 & 0 & 0 & 0 \\
\hline & \multirow{6}{*}{ Links externos } & \begin{tabular}{|l} 
Con bodegas \\
de la \\
Denominación \\
de Origen \\
\end{tabular} & 13,5 & 28,57 & 0 & 5,56 & 14,29 \\
\hline & & \begin{tabular}{|l|} 
Con bodegas \\
de otra \\
Denominación \\
de Origen \\
\end{tabular} & 1,4 & 0 & 0 & 0 & 0 \\
\hline & & $\begin{array}{l}\text { Con Consejo } \\
\text { Regulador }\end{array}$ & 17,6 & 14,29 & 60 & 16,67 & 3,57 \\
\hline & & De restaurantes & 27 & 0 & 0 & 5,56 & 3,57 \\
\hline & & \begin{tabular}{|l}
$\mathrm{De}$ \\
alojamientos
\end{tabular} & 1,4 & 0 & 0 & 5,56 & 0 \\
\hline & & \begin{tabular}{|l} 
De lugares, \\
festivales, \\
cultura, ... \\
\end{tabular} & 10,8 & 21,43 & 20 & 11,11 & 3,57 \\
\hline \multirow[t]{2}{*}{ Relaciones } & \multirow[t]{2}{*}{ Comunicación } & $\begin{array}{l}\text { Apartado de } \\
\text { contacto para } \\
\text { sugerencias, } \\
\text { consultas, ... } \\
\end{array}$ & 89,2 & 85,71 & 100 & 94,44 & 82,14 \\
\hline & & Newsletter & 4,1 & 0 & 0 & 0 & 7,14 \\
\hline
\end{tabular}




\begin{tabular}{|c|c|c|c|c|c|c|c|}
\hline Dimensión & Subdimensión & Items & ARAGÓN & Calatayud & $\begin{array}{c}\text { Campo } \\
\text { Borja }\end{array}$ & Cariñena & Somontano \\
\hline \multirow{15}{*}{ Relaciones } & \multirow{13}{*}{ Comunicación } & $\begin{array}{l}\text { Foro/Libro } \\
\text { visitas }\end{array}$ & 4,1 & 7,14 & 0 & 0 & 7,14 \\
\hline & & Club del vino & 9,5 & 0 & 0 & 5,56 & 21,43 \\
\hline & & $\begin{array}{l}\text { Área específica } \\
\text { para clientes, } \\
\text { socios, } \\
\text { distribuidores }\end{array}$ & 17,6 & 0 & 0 & 16,67 & 32,14 \\
\hline & & $\begin{array}{l}\text { Perfil personal/ } \\
\text { Registro } \\
\text { usuario }\end{array}$ & 21,6 & 7,14 & 0 & 27,78 & 32,14 \\
\hline & & $\begin{array}{l}\text { Posibilidad } \\
\text { dispositivo } \\
\text { móvil }\end{array}$ & 2,7 & 7,14 & 0 & 5,56 & 0 \\
\hline & & $\begin{array}{l}\text { Redes sociales } \\
\text { (al menos } \\
\text { una de las } \\
\text { siguientes) }\end{array}$ & 56,8 & & & & \\
\hline & & $\mathrm{B} \log$ & 9,5 & 7,14 & 10 & 0 & 7,14 \\
\hline & & Facebook & 56,8 & 50 & 100 & 22,22 & 71,43 \\
\hline & & Twitter & 36,5 & 35,71 & 70 & 16,67 & 42,86 \\
\hline & & Pinterest & 6,85 & 0 & 0 & 11,11 & 10,71 \\
\hline & & Instagram & 8,1 & 14,29 & 0 & 11,11 & 7,14 \\
\hline & & $\mathrm{G}+$ & 10,8 & 14,29 & 0 & 5,56 & 10,71 \\
\hline & & Youtube & 18,9 & 35,71 & 20 & 5,56 & 21,43 \\
\hline & \multirow[t]{2}{*}{$\begin{array}{l}\text { Marketing } \\
\text { Viral }\end{array}$} & $\begin{array}{l}\text { Recomendar la } \\
\text { web }\end{array}$ & 14,9 & 7,14 & 20 & 16,67 & 17,86 \\
\hline & & $\begin{array}{l}\text { Envío postales } \\
\text { desde web }\end{array}$ & 0 & 0 & 0 & 0 & 0 \\
\hline \multirow{8}{*}{$\begin{array}{l}\text { Confianza, } \\
\text { Diseño y } \\
\text { Usabilidad }\end{array}$} & $\begin{array}{l}\text { Copyright y } \\
\text { Seguridad }\end{array}$ & $\begin{array}{l}\text { Política } \\
\text { privacidad/ } \\
\text { Derechos } \\
\text { Reservados/ } \\
\text { Aviso Legal }\end{array}$ & 60,8 & 78,57 & 50 & 66,67 & 53,57 \\
\hline & & Copyright & 44,6 & 35,71 & 60 & 55,56 & 21,43 \\
\hline & & Cookies & 29,7 & 35,71 & 20 & 22,22 & 28,57 \\
\hline & \multirow{5}{*}{$\begin{array}{l}\text { Temporalidad } \\
\text { y Marca }\end{array}$} & $\begin{array}{l}\text { Fecha } \\
\text { actualización } \\
\text { web }\end{array}$ & 5,4 & 0 & 0 & 0 & 0 \\
\hline & & $\begin{array}{l}\text { Dominio } \\
\text { marca.com/ } \\
\text { marca.net }\end{array}$ & 78,4 & 78,57 & 90 & 83,33 & 75 \\
\hline & & $\begin{array}{l}\text { Dominio } \\
\text { marca.es/ } \\
\text { marca.es }\end{array}$ & 20,3 & 14,29 & 10 & 11,11 & 28,57 \\
\hline & & Otro dominio & 1,4 & 0 & 0 & 5,56 & 0 \\
\hline & & $\begin{array}{l}\text { E-mail } \\
\text { propio/...marca }\end{array}$ & 89,2 & 78,57 & 100 & 94,44 & 89,29 \\
\hline
\end{tabular}




\begin{tabular}{|c|c|c|c|c|c|c|c|}
\hline Dimensión & Subdimensión & Items & ARAGÓN & Calatayud & $\begin{array}{c}\text { Campo } \\
\text { Borja }\end{array}$ & Cariñena & Somontano \\
\hline \multirow{11}{*}{$\begin{array}{l}\text { Confianza, } \\
\text { Diseño y } \\
\text { Usabilidad }\end{array}$} & \multirow{11}{*}{ Navegabilidad } & $\begin{array}{l}\text { Número } \\
\text { idiomas } \\
\text { disponibles } \\
\text { (Más de un } \\
\text { idioma) }\end{array}$ & 68,9 & & & & \\
\hline & & Solo Español & 31,1 & 21,43 & 20 & 16,67 & 46,43 \\
\hline & & $\begin{array}{l}\text { Español e } \\
\text { Ingles }\end{array}$ & 48,6 & 57,14 & 70 & 38,89 & 42,86 \\
\hline & & 3 a 5 idiomas & 16,2 & 14,29 & 10 & 33,33 & 10,71 \\
\hline & & $\begin{array}{l}6 \text { o más } \\
\text { idiomas }\end{array}$ & 2,7 & 0 & 0 & 11,11 & 0 \\
\hline & & $\begin{array}{l}\text { Euskera, } \\
\text { catalán o } \\
\text { valenciano }\end{array}$ & 0 & 0 & 0 & 0 & 0 \\
\hline & & $\begin{array}{l}\text { Función de } \\
\text { búsqueda }\end{array}$ & 14,9 & 14,29 & 20 & 11,11 & 17,86 \\
\hline & & $\begin{array}{l}\text { Preguntas } \\
\text { frecuentes }\end{array}$ & 2,7 & 0 & 10 & 0 & 3,57 \\
\hline & & $\begin{array}{l}\text { Menús } \\
\text { desplegables }\end{array}$ & 47,3 & 50 & 50 & 38,89 & 50 \\
\hline & & $\begin{array}{l}\text { Volver a la } \\
\text { home }\end{array}$ & 75,7 & 50 & 90 & 83,33 & 75 \\
\hline & & Mapa del sitio & 44,6 & 21,43 & 20 & 50 & 67,86 \\
\hline
\end{tabular}

Recordemos que la primera dimensión "Información y Procesos" está integrada por 4 sub-dimensiones con sus respectivos criterios de evaluación. Los resultados obtenidos muestran que la Información de contacto de la bodega aparece prácticamente en todas las webs analizadas. Así, la dirección física, el e-mail y el teléfono están presentes en todas las webs. Los porcentajes disminuyen en lo relativo a la presencia de un mapa de ubicación de la bodega y del número de fax. El contenido de la web en relación a la Presentación de la Empresa parece ser escaso. La información general sobre el negocio desarrollado por las bodegas aparece en prácticamente todas las webs $(95,9 \%)$ al igual que fotos de bodega y de los viñedos $(82,4 \%)$. Las noticias de prensa, así como la presencia de algún tipo de descargable están presentes en torno al $50 \%$ de las webs. Sin embargo, emergen como aspectos que deben ser mejorados la información que se proporciona sobre los distribuidores y puntos de venta de los vinos, así como sobre los días y horarios de apertura de las bodegas. Estos dos elementos son muy importantes si se desean alcanzar objetivos de marketing como la venta directa en la bodega y el desarrollo del turismo del vino. La Información sobre el Producto parece estar más desarrollada que la información sobre el negocio. Así, la mayoría de las bodegas muestran fotos de las botellas $(97,3 \%)$, proporcionan un listado de sus vinos $(95,9 \%)$ así como la descripción de los mismos $(93,2 \%)$. En una menor proporción se presentan fotos de las etiquetas $(85,1 \%)$. La información sobre los precios de los vinos y sobre los premios recibidos es escasa, ya que sólo se muestra en torno al 35\% de las webs. La presencia de comentarios de los clientes también es baja, 
aunque este hecho puede carecer de importancia si se fomenta la comunicación interactiva a través de otros medios. Finalmente, la Venta de Productos y Reserva de Actividades a través de las webs también parece que podría ser mejorada, ya que sólo el 43,2\% ofrece la posibilidad de comprar productos a través de la web. A esto hay que unirle el hecho de que todo el proceso relacionado con la compra, pago y seguimiento del pedido debería ser mejorado.

En relación al "Valor Agregado" de la web se detecta un escaso nivel de orientación hacia la integración. Así, el análisis del contenido de las webs pone de manifiesto que no se lleva a cabo una integración interna ya que, por ejemplo, se ofrece escasa información sobre otros productos ofertados $(21,6 \%)$ distintos al vino. Esta baja integración interna queda patente en el contenido relativo a la Información sobre Servicios y Actividades, que emerge como un contenido susceptible de mejora. Así, se observa que, en general, son pocas las webs (en torno al 20\%) que ofrecen información sobre la posibilidad de realizar visitas a las bodegas, días y horarios de apertura, sobre catas y otros eventos relacionados con las bodegas. Aunque son muy pocas las webs en las que se indica el precio de las visitas, éste se sitúa entre los 2 y los 15 euros, aunque hay bodegas que no cobran por visitarlas. A todo esto, se debe unir un escaso desarrollo de la integración externa con otros negocios. Son pocas las webs que muestran información general sobre la región, aunque se subsana ligeramente con la presencia de links con servicios de la zona como, por ejemplo, restaurantes, alojamientos, festivales. Por tanto, se puede deducir del análisis de los indicadores evaluados que el desarrollo de la integración externa, a través de redes de negocio, es escaso.

Las webs analizadas sí que parecen estar siendo empleadas para establecer "Relaciones" con los clientes a través de una comunicación interactiva. Un alto porcentaje de las webs $(89,2 \%)$ proporcionan un apartado de contacto para que los clientes puedan hacer llegar a las bodegas sus sugerencias y consultas. Además, se emplean las redes sociales, principalmente Facebook (56,8\%) seguida por Twitter (36,5\%). El desarrollo del "marketing viral" debe mejorarse, ya que la posibilidad de recomendar la propia página web está presente únicamente en el $14,9 \%$ de las webs.

Por último, destacar los aspectos "Técnicos" de las webs. Se observa que son dos los aspectos más empleados para generar confianza e incrementar así la posibilidad de creación de relaciones con los clientes, la política de privacidad y el uso del copyright. Destacar la práctica ausencia de la fecha de actualización en todas las webs analizadas, ya que sólo está presente en el 5,4\%. Uno de los aspectos más desarrollados relacionados con la navegabilidad es el de los idiomas, ya que más de la mitad de las webs $(68,9 \%)$ suelen emplear dos idiomas, español e inglés. Incluso existen webs que ofrecen la posibilidad de navegar en tres idiomas. Junto a esto, destaca el elevado porcentaje de webs que ofrecen la posibilidad de retornar directamente a la página principal $(75,7 \%)$. El resto de elementos relacionados con el diseño y la usabilidad muestran un escaso desarrollo.

\subsubsection{Análisis clúster}

Con el objetivo de detectar la existencia de grupos de páginas webs con distintos perfiles atendiendo a su contenido, con independencia de la D.O. de la bodega que las 
emplee, se procede a la realización de un análisis Clúster. Este análisis permite detectar la existencia de grupos o conglomerados, lo más homogéneos en sí y lo más heterogéneos entre sí con respecto a la distribución de las variables analizadas (Hair et al., 1999). De los posibles algoritmos aplicables se ha empleado el método Ward y la distancia euclídea al cuadrado. Para analizar la significatividad de las diferencias entre los grupos se ha realizado el correspondiente análisis de tablas de contingencia, aplicándose el test de Chi-cuadrado. Los resultados obtenidos, mostrados en la Tabla 3, ponen de manifiesto la existencia de dos grupos diferenciados de sitios web. El primero de ellos es el mayoritario ya que está integrado por el $72,6 \%$ de las webs analizadas (53 webs), mientras que el segundo agrupa al $27,4 \%$ restante (20 webs). En la Tabla 3 se muestra el \% de webs que poseen el contenido evaluado en cada grupo, así como si las diferencias entre los dos grupos detectados son o no significativas.

\section{Tabla 3 \\ RESULTADOS ANÁLISIS CLÚSTER (EN \%)}

\begin{tabular}{|c|c|c|c|c|}
\hline & \multirow{3}{*}{$\begin{array}{c}\begin{array}{c}\text { Grupo } 1 \\
(72,6 \%)\end{array} \\
100\end{array}$} & \multirow{3}{*}{$\begin{array}{c}\begin{array}{c}\text { Grupo } 2 \\
(27,4 \%)\end{array} \\
100 \\
\end{array}$} & \multirow{3}{*}{ Dif } \\
\hline & & & & \\
\hline \multirow{5}{*}{$\begin{array}{l}\text { Dirección de } \\
\text { Contacto }\end{array}$} & E-mail & & & \\
\hline & Dirección física & 100 & 100 & \\
\hline & Teléfono & 100 & 100 & \\
\hline & Fax & 73,6 & 85 & \\
\hline & Mapa & 79,2 & 100 & 0,021 \\
\hline \multirow{7}{*}{$\begin{array}{l}\text { Presentación } \\
\text { Empresa }\end{array}$} & Información sobre el Negocio & 94,3 & 100 & \\
\hline & Noticias y Prensa & 43,4 & 80 & 0,005 \\
\hline & $\begin{array}{l}\text { Información sobre Distribuidores y/o } \\
\text { Puntos de Venta }\end{array}$ & 17 & 50 & 0,006 \\
\hline & Días y horarios de apertura & 5,7 & 60 & 0,000 \\
\hline & Al menos un descargable & 39,6 & 70 & 0,019 \\
\hline & Vídeos & 9,4 & 35 & 0,014 \\
\hline & Tour o Recorrido virtual & 1,9 & 10 & \\
\hline \multirow{8}{*}{$\begin{array}{l}\text { Información } \\
\text { Vinos }\end{array}$} & Listado de los vinos & 94,3 & 100 & \\
\hline & Descripción de los vinos & 90,6 & 100 & \\
\hline & Fotos de las botellas de vinos & 96,2 & 100 & \\
\hline & Fotos de las etiquetas & 81,1 & 95 & 0,048 \\
\hline & Listado de premios de los vinos & 28,3 & 45 & \\
\hline & Comentarios de clientes & 3,8 & 10 & \\
\hline & Información de precios de los vinos & 26,4 & 60 & 0,009 \\
\hline & Información de otros productos ofrecidos & 11,3 & 50 & 0,001 \\
\hline
\end{tabular}




\begin{tabular}{|c|c|c|c|c|}
\hline & & $\begin{array}{l}\text { Grupo } 1 \\
(72,6 \%)\end{array}$ & $\begin{array}{l}\text { Grupo } 2 \\
(27,4 \%)\end{array}$ & Dif \\
\hline \multirow{10}{*}{$\begin{array}{l}\text { Venta } \\
\text { Productos }\end{array}$} & Compra productos por la web & 32,1 & 70 & 0,004 \\
\hline & $\begin{array}{l}\text { Imprimir hoja de pedidos y mandarla por } \\
\text { fax }\end{array}$ & 0 & 10 & 0,072 \\
\hline & Petición a través de mail & 26,4 & 55 & 0,023 \\
\hline & Envio gratuito por compra & 7,5 & 30 & 0,021 \\
\hline & Carro de compra & 26,4 & 60 & 0,009 \\
\hline & Tiempo de entrega & 1,9 & 15 & 0,060 \\
\hline & Zona de entrega & 7,5 & 40 & 0,002 \\
\hline & Pedido y pago on-line & 24,5 & 55 & 0,015 \\
\hline & $\begin{array}{l}\text { Reserva de actividades por teléfono, mail, } \\
\text { on-line }\end{array}$ & 1,9 & 70 & 0,000 \\
\hline & De posibilidad visitas & 7,5 & 95 & 0,000 \\
\hline \multirow{10}{*}{$\begin{array}{l}\text { Información } \\
\text { Servicios y } \\
\text { Actividades }\end{array}$} & Sobre tours o Rutas del Vino & 9,4 & 65 & 0,000 \\
\hline & Sobre catas & 1,9 & 65 & 0,000 \\
\hline & Sobre eventos relacionados con la bodega & 1,9 & 65 & 0,000 \\
\hline & Sobre restaurante propio & 0 & 25 & 0,001 \\
\hline & Sobre alojamiento propio & 1,9 & 5 & \\
\hline & Sobre venta en bodega & 0 & 45 & 0,000 \\
\hline & Sobre museo o sala de arte & 0 & 5 & \\
\hline & $\begin{array}{l}\text { Sobre biblioteca o centro de } \\
\text { documentación propio }\end{array}$ & 0 & 0 & \\
\hline & $\begin{array}{l}\text { Sobre sala de reuniones, de conferencia o } \\
\text { wine bar propio }\end{array}$ & 1,9 & 5 & \\
\hline & Otras actividades ofrecidas & 0 & 55 & 0,000 \\
\hline \multirow{5}{*}{$\begin{array}{l}\text { Información } \\
\text { Región }\end{array}$} & De restaurantes en la zona & 0 & 10 & 0,072 \\
\hline & De alojamiento en la zona & 1,9 & 0 & \\
\hline & De lugares, festivales, cultura, ... & 0 & 30 & 0,000 \\
\hline & Calendario de eventos & 0 & 0 & \\
\hline & Del cima diario & 0 & 0 & \\
\hline \multirow{6}{*}{ Links Externos } & $\begin{array}{l}\text { Con bodegas de la Denominación de } \\
\text { Origen }\end{array}$ & 9,4 & 25 & 0,093 \\
\hline & $\begin{array}{l}\text { Con bodegas de otra Denominación de } \\
\text { Origen }\end{array}$ & 1,9 & 0 & \\
\hline & Con Consejo Regulador & 18,9 & 15 & \\
\hline & De restaurantes & 1,9 & 5 & \\
\hline & De alojamientos & 1,9 & 0 & \\
\hline & De lugares, festivales, cultura, ... & 13,2 & 5 & \\
\hline
\end{tabular}




\begin{tabular}{|c|c|c|c|c|}
\hline & \multirow{4}{*}{$\begin{array}{c}\begin{array}{c}\text { Grupo } 1 \\
(72,6 \%)\end{array} \\
88,7\end{array}$} & \multirow{4}{*}{$\begin{array}{c}\begin{array}{c}\text { Grupo } 2 \\
(27,4 \%)\end{array} \\
95\end{array}$} & \multirow{4}{*}{ Dif } \\
\hline & & & & \\
\hline & & & & \\
\hline \multirow{9}{*}{ Comunicación } & $\begin{array}{l}\text { Apartado de contacto para sugerencias, } \\
\text { consultas, ... }\end{array}$ & & & \\
\hline & Newsletter & 1,9 & 5,5 & \\
\hline & Foro/Libro visitas & 1,9 & 10 & \\
\hline & Club del vino & 3,8 & 20 & 0,044 \\
\hline & $\begin{array}{l}\text { Área específica para clientes, socios, } \\
\text { distribuidores }\end{array}$ & 11,3 & 30 & 0,063 \\
\hline & Perfil personal/Registro usuario & 11,3 & 45 & 0,003 \\
\hline & Posibilidad dispositivo móvil & 3,8 & 0 & \\
\hline & Blog & 11,3 & 5 & \\
\hline & $\begin{array}{l}\text { Redes sociales (Facebook, twitter, blog, } \\
\text { etc) }\end{array}$ & 47,2 & 80 & 0,011 \\
\hline \multirow{2}{*}{ Marketing Viral } & Recomendar la web & 13,2 & 20 & \\
\hline & Enviar postales & 0 & 0 & \\
\hline \multirow{3}{*}{ Seguridad } & $\begin{array}{l}\text { Política privacidad/Derechos Reservados/ } \\
\text { Aviso Legal }\end{array}$ & 52,8 & 80 & 0,030 \\
\hline & Copyright & 45,3 & 40 & \\
\hline & Cookies & 18,9 & 55 & 0,004 \\
\hline \multirow{5}{*}{$\begin{array}{l}\text { Temporalidad y } \\
\text { Marca }\end{array}$} & Fecha actualización web & 5,7 & 5 & \\
\hline & Dominio marca.com/marca.net & 83 & 70 & \\
\hline & Dominio marca.es/marca.es & 15,1 & 30 & \\
\hline & Otro dominio & 1,9 & 0 & \\
\hline & E-mail propio/...marca & 88,7 & 90 & \\
\hline \multirow{7}{*}{ Navegabilidad } & Idioma sólo Español & 35,8 & 20 & 0,019 \\
\hline & Más de un idioma & 64,2 & 80 & \\
\hline & Función de búsqueda & 7,5 & 30 & 0,021 \\
\hline & Preguntas frecuentes & 0 & 10 & 0,072 \\
\hline & Menús desplegables & 35,8 & 75 & 0,003 \\
\hline & Volver a la home & 71,7 & 85 & \\
\hline & Mapa del sitio & 30,2 & 80 & 0,000 \\
\hline
\end{tabular}

Como se puede observar en la Tabla 3, el Grupo 2 está integrado por aquellas webs que, en general, poseen una mayor presencia en todos los criterios de evaluación analizados. Este hecho indica que el Grupo 2 se encuentra integrado por las webs de aquellas bodegas que ofrecen un mayor contenido a los usuarios, lo que es un reflejo del nivel de desarrollo de su negocio atendiendo a los objetivos de marketing que se desean alcanzar. 
Destacar que los datos básicos para que los clientes puedan tomar la iniciativa y contactar con las bodegas a través de distintos medios están presentes en los dos grupos. Únicamente emerge una diferencia significativa en el criterio relativo a un mapa que informe sobre el acceso a la bodega, el cual está más presente en el Grupo 2.

La dimensión "Información y Procesos" englobaba el contenido indicativo de una orientación de la web a proporcionar información y facilitar la realización de transacciones. Así, el contenido relacionado con la información que se proporciona, tanto sobre la bodega, sus vinos y otros servicios y actividades, está más presente en el Grupo 2, existiendo diferencias significativas en la mayoría de los criterios empleados. Como se muestra en la Tabla 3, la información que ofrecen las webs integradas en el Grupo 1 sobre la bodega debe ser mejorada, especialmente en lo relacionado a las noticias de prensa que muestran, la información sobre distribuidores y sobre horarios de apertura. La información sobre los vinos es más similar entre los dos grupos, ya que sólo emergen diferencias significativas en tres de los ocho criterios de evaluación analizados. Así, el Grupo 1 debería mejorar la información sobre las fotos de las etiquetas, precios de los vinos y sobre otros productos que ofrezca. Las principales diferencias entre los dos grupos detectados se encuentran en los criterios relacionados con facilitar las transacciones a través de la web, esto es, venta de vinos y de otros productos. La consecución de este objetivo transaccional debe ser claramente mejorada en las webs del Grupo 1 ya que, como se observa en la Tabla 3, emergen diferencias significativas en todos los criterios analizados, estando todos ellos más presentes en el Grupo 2.

La consecución de una comunicación interactiva con los clientes a través de la web, recogida a través de los criterios de evaluación correspondientes a la dimensión Relaciones, debe ser mejorada en los dos grupos. A pesar de ello, se observa que está algo más presente en el Grupo 2 al existir diferencias significativas en el contenido relativo a un área específica para clientes, un club del vino, el registro de usuario y el uso de redes sociales.

La integración interna está claramente más desarrollada en el Grupo 2, ya que se ofrece más información sobre los distintos bienes y servicios relacionados con la bodega que configura la oferta. Este sería el caso de, por ejemplo, las catas, el restaurante propio y las visitas. La integración externa a través de relaciones con otras empresas parece estar escasamente desarrollada por las bodegas de los dos grupos atendiendo a los criterios evaluados en las webs. Así, de los once criterios únicamente emergen diferencias significativas en tres de ellos. Este resultado parece poner de manifiesto que existe una mayor integración externa en las webs de las bodegas del Grupo 2, ya que ofrecen más información sobre restaurantes de la zona y sobre los elementos culturales presentes en la misma, aportando además links con otras bodegas de la misma zona.

El mayor desarrollo de las webs del Grupo 2, y por lo tanto de más objetivos de marketing, también se refleja en sus aspectos técnicos. Así, estas webs poseen más criterios destinados a generar seguridad y confianza. Además, poseen una mejor navegabilidad, ya que presentan en mayor proporción, por ejemplo, función de búsqueda, apartado de preguntas frecuentes, menús desplegables y mapa del sitio web. 


\section{CONCLUSIONES, LIMITACIONES E IMPLICACIONES PARA LA GESTIÓN}

El importante crecimiento de Internet proporciona una gran oportunidad para que las pequeñas y medianas bodegas puedan sobrevivir en mercados altamente competitivos. Para ello, pueden desarrollar distintas estrategias de marketing online cuyos objetivos se centren en ofrecer información sobre el negocio y el producto, incrementar sus ventas, a través del comercio electrónico y de la venta directa, o ir más allá, desarrollando distintas redes de negocios. Para ello, el desarrollo de relaciones y de una comunicación interactiva con sus clientes constituye un factor crítico para que las bodegas puedan alcanzar ventajas competitivas (Sparkes y Thomas, 2001).

El uso de Internet como fuente de información antes de tomar la decisión de compra que, en la actualidad, realizan los consumidores convierte a las webs en una de las principales herramientas para que las bodegas puedan alcanzar los objetivos de marketing establecidos. Este hecho queda patente en el posicionamiento SEO de las bodegas aragonesas. Así, los resultados recogidos de Google ponen de manifiesto que, cuando se busca información sobre el vino de Aragón, son cinco los tipos de páginas distintos que copan los primeros resultados de búsqueda: las de las bodegas, las de tienda online de vinos/ bodegas; las institucionales (turismo, D.O.); las de medios de comunicación y fuentes de información; y las redes Sociales. Concretamente, cerca del 28\% de los resultados corresponden a tiendas online de vinos, mientras que las webs de las bodegas copan cerca del 20\% (O10media, 2017). Por tanto, resulta vital tener presencia en Internet y, en función de los objetivos de negocio perseguidos, mostrar distintos contenidos en las webs.

La investigación realizada muestra que las bodegas analizadas son conscientes de la importancia de Internet como elemento que les brinda oportunidades de negocio. Así, a pesar de que la estructura del sector está integrada fundamentalmente por pequeñas y medianas bodegas con recursos limitados, la mayor parte de ellas posee una página web activa. Sin embargo, a pesar de esta alta tasa de penetración de las webs como herramienta de marketing, la mayoría de los criterios de evaluación analizados resultan ser susceptibles de mejora.

Así, los criterios que reflejan la orientación de la web como transmisora de información emergen como los más desarrollados, ya que todas las webs poseen la información de contacto básica. Sin embargo, parece deducirse que las webs se están empleando más como un folleto electrónico que como una herramienta de marketing dinámica y eficiente. En general, las webs ofrecen una información bastante completa sobre sus productos, mostrando fotos de las botellas, de las etiquetas y una descripción de los vinos. Por tanto, los clientes potenciales sí que pueden obtener información previa a la compra sobre las características de los vinos, así como sobre otros elementos educacionales como premios o noticias de los vinos. Sin embargo, toda esta información parece que no se aprovecha adecuadamente a través del uso de la web como canal de venta. Menos de la mitad de las webs ofrecen la posibilidad de realizar compras online, siendo este porcentaje inferior al que existe en el mercado español. Además, son pocas las webs que ofrecen información sobre los distribuidores de los productos de la bodega. Estos datos pueden explicar la baja presencia de los precios de los vinos en las webs. Al no diseñar una web con un contenido transaccional, se evita que los clientes potenciales puedan realizar comparaciones de precios previas a la 
compra. Pero, las bodegas analizadas están perdiendo así una importante oportunidad de negocio al no emplear el canal de venta online que le permita entrar en mercados distintos a los habituales, en muchos de los cuales es difícil encontrar un proveedor oficial. Esta escasa orientación transaccional presente en el contenido de las webs podría deberse a varias causas. Por una parte, la escasa disponibilidad de recursos por parte de las bodegas, quienes deberían destinar recursos, tanto humanos como técnicos, para gestionar los pedidos online así como perfeccionar el proceso de compra proporcionado por la web (actualización de la web, carro de compra, pago seguro, seguimiento de la compra). La falta de recursos y/o la ausencia de concienciación de los bodegueros sobre la rentabilidad de este canal podrían explicar este hecho. Por otra parte, puede deberse a que las bodegas no quieren entrar en conflicto con sus otros canales de distribución y, para evitarlo, los precios de venta a través de la web deberían ser mayores que los fijados por sus distribuidores.

Sin embargo, aunque parece que no aprovechan las oportunidades proporcionadas por la venta online, sí que parecen empezar a estar concienciados de la importancia de establecer relaciones interactivas con los clientes. Aunque también es un elemento susceptible de mejora, se observa una alta presencia de las redes sociales en las webs de las bodegas, especialmente de Facebook y Twitter, siendo menos numerosa la presencia de perfiles en Pinterest, Linkedin y Youtube. Esto puede deberse debido a que estas últimas herramientas son más desconocidas o requieren inversión económica para publicar contenido de calidad. Estas herramientas deben ser gestionadas por profesionales de la comunicación y/o community managers a tiempo completo, lo cual requiere recursos económicos adicionales. Así, son numerosas las bodegas que encargan estas acciones a personal de la propia bodega sin la cualificación necesaria, lo cual puede originar errores en la política de comunicación (Matellanes, 2014). A pesar de esto, la existencia de contenidos que permitan una comunicación interactiva ofrece a las bodegas la oportunidad de detectar los deseos de la demanda e ir ajustando la oferta de sus productos. De esta manera podrán alcanzar mayores niveles de satisfacción y de lealtad.

Entre las demandas de los clientes se encuentra el deseo de experimentar la cultura del vino, por lo que las bodegas se enfrentan a una importante oportunidad de negocio. La integración, tanto interna como externa, ofrece la posibilidad de obtener ingresos complementarios a la venta del vino a través de cualquier canal. Esto lo pueden realizar las bodegas asumiendo ellas mismas las actividades relacionadas con el turismo del vino (integración interna) o estableciendo redes con negocios de la zona que permitan el desarrollo de un producto turístico que proporcione una experiencia completa. Los beneficios que se derivan del desarrollo de este tipo de turismo parecen estar empezando a ser valorados por determinadas bodegas. Fomentar las visitas a la bodega puede constituir otro importante factor para incrementar las ventas a través de la venta directa.

Atendiendo a los contenidos presentes en las webs, se observa la existencia de dos grupos claramente diferenciados. El más numeroso es el que ofrece una web menos evolucionada, cuyos objetivos están fundamentalmente orientados a proporcionar información. El segundo grupo se corresponde con webs más evolucionadas, cuyas bodegas persiguen unos objetivos de marketing más ambiciosos que quedan reflejados en el contenido de las webs. Estas webs presentan todas las orientaciones detectadas en la literatura, aunque siguen teniendo espacio para la mejora. 
Finalmente destacar que la web debe resultar funcional y fácil de emplear, de tal manera que la visita a la web resulte una experiencia satisfactoria. Aunque son varios los factores que deben ser mejorados, no parecen detectarse problemas importantes en el diseño y uso de las webs analizadas. Sí que es importante que se incluya la fecha de actualización de la web para poder transmitir confianza tanto para la realización de una compra como para informarse de las actividades relacionadas con el turismo del vino que se podrían llegar a realizar. Destacar que se han detectado relaciones significativas entre la frecuencia de actualización de la web y las ventas directas y actividades relacionadas con el turismo del vino (Stricker, Mueller y Summer, 2007). Esta es una limitación de este estudio, ya que no se ha realizado una evaluación técnica.

Por lo tanto, parece que los primeros pasos del marketing online sí que están presentes, aunque se están perdiendo importantes oportunidades de negocio. Por lo tanto, futuras investigaciones deberían abordar los retornos que se derivan de la presencia de webs como herramienta de su estrategia de marketing. Así, sería importante analizar, por ejemplo, los elementos que provocan que los bodegueros no estén fomentando la venta online de sus productos, así como el desarrollo de redes de negocio para desarrollar turismo del vino, a través de la integración interna o externa.

\section{REFERENCIAS}

AHRENS, J. y COYLE, J.R. (2011): “A Content Analysis of Registration Processes on Websites", Journal of Interactive Advertising, vol. 11 (2), pp. 12-26.

ALONSO, A.D., BRESSAN, A., O’SHEA, M. y KRAJSIC, V. (2013): “Website and Social Media Usage: Implications for the Further Development of Wine Tourism, Hospitality and the Wine Sector", Tourism Planning y Development, vol. 10 (3), pp. 229-248.

AMARO, S., BARROCO, C. y ANTUNES, J. (2010): “The Internet as an Important Tool in Developing the Dao Wine Route Network: A Study of the Dao Wine Route Websites", en Proceeding of the Advances in Tourism Research 2010. ISAK y Universidad de Oviedo, pp. 717-724.

BAUER, H.H., GRETHER, M. y LEACH, M. (2002): "Building Customer Relations over the Internet. Industrial Marketing Management”, vol. 31 (2), pp. 155-163.

BEAMES, G. (2003): "The Rock, the Reef and the Grape: the Challenges of Developing Wine Tourism in Regional Australia", Journal of Vacation Marketing, vol. 9 (3), pp. 205-212.

BELANGER, F., FAN, W., SCHAUPP, L.C., KRISHEN, A., EVERHART, J., POTEET, D. y NAKAMOTO, K. (2006): "Website Success Metrics: Addressing the Duality of Goals", Communications of the ACM, vol. 49 (12), pp. 114-116.

BELLMAN, S. y ROSSITIER, J.R. (2004): “The Web Site Schema", Journal of Interactive Advertisig, vol. 4 (2), pp. 38-48.

BERELSON, B, (1952): Content Analysis in Communication Research. New York, Free Press.

BERNET, A. y STRICKER, S. (2003): “German Wineries on the Web: A survey of Web Sites of Mosel-Saar-Ruwer and Pfalz Wineries", en Proceedings of the Wine Marketing Colloquium, July, pp. 26-27, Adelaide, Australia. 
BEVERLAND, M., JAMES, K., JAMES, M., PORTER, C. y STACE, G. (1998): “Wine Tourism: Missed Opportunities in West Auckland", The Australian and New Zealand Wine Industry Journal, vol. 13 (4), pp. 403-407.

BRUWER, J. y WOOD, G. (2005): "The Australian Online Wine-Buying Consumer: Motivational and Behavioural Perspectives", Journal of Wine Research, vol. 16 (3), pp. 193-211.

BURGESS, L. y COOPER, J. (1999): "MICA: A Model for Classification of Business Adoption of Internet Commerce", en Proceedings of the 12th International Bled Electronic Commerce Conference, Bled, Slovenia, June 7-9.

BURGESS, L. y COOPER, J. (2000): "Extending the Viability of MICA (Model of Internet Commerce Adoption) as a Metric for Explaining the Process of Business Adoption of Internet Commerce", en Proceedings of the International Conference on Telecommunications and Electronic Commerce, Dallas, Texas, November.

CAMPRUBÍ, R. y GALÍ, N. (2015): “Análisis Exploratorio de la Funcionalidad de las Páginas Web de los Viñedos del Priorat: El caso de las bodegas de la Ruta del Vino de la Denominación de Origen de Calidad Priorat", Boletín de la Asociación de Geógrafos Españoles, $n^{\circ}$ 68, pp. 483-488.

DAVIDSON, R.A. (2002): "Development of an Industry Specific Website Evaluation Framework for the Australian Wine Industry", Research Paper Series: 02-9. ISSN: 1441-3906.

DAVIDSON, R.A. (2004): “A Study of Australian Winery Websites”, in Proceedings of The Collaborative E-Commerce Technology and Research Conference (CollECTeR2004) May 7-8, 2004, Adelaide, Australia.

DAVIDSON, R.A. (2008): Changes in Australian Winery Websites over a Five Year Period, in Proceedings of $21^{\text {st }}$ Bled eConference eCollaboration: Overcoming Boundaries Through Multi-Channel Interaction, June 15-18, Bled, Slovenia.

EVERARD, A. y GALLETTA, D.F. (2006): "How Presentation Flaws Affect Perceived Site Quality, Trust, and Intention to Purchase from an Online Store", Journal of Management Information Systems, vol. 22 (3), pp. 55-95.

FERREIRA, G.F.C. y FERREIRA, J.P.C. (2013): “The Virginia Wineries' Websites: An Evaluation", in Proceedings of the Southern Agricultural Economicas Association Annual Meeting, Orlando, Florida, 3-5 Febrero.

FORRESTER RESEARCH, I. (2009): Every Second Counts: How Website Performance Impacts Shopper Behavior, in http://www.getelastic.com/performance/(accessed)

GEBAUER, J. y GINSBURG, M. (2003): "The US Wine Industry and the Internet: An Analysis of Success Factors for Online Business Models", Electronic Markets, vol. 13 (1), pp. 59-66.

GETZ, D., CARLSEN, J., BROWN, G. y HAVITZ, M. (2008): "Wine Tourism and Consumers", in A.G. Woodside, y D. Martin (Eds.), Tourism Management: Analysis, Behaviour and Strategy. Cambridge, MA: CABI, pp. 245-268.

GILMORE, A., GALLAGHER, D. y HENRY, S. (2007): "E-marketing and SMEs: Operational Lessons for the Future", European Business Review, vol. 19 (3), pp. 234-247.

GIRAUD-HÉRAUD, E., SOLER, L.G. y TANGUY, H. (2001): “Internet et la Distribution de Biens Physique. Analyse de l'émergence de Nouvelles Structures Verticales dans le Secteur du Vin", Revue économique, 52 (october), pp. 213-232. 
GOODMAN, S. (2003): "A Framework for the Implementation of (internet) Marketing by the Wine Business", en Proceedings Colloquium 2003.

GURÄU, C. y DUSQUENOIS, F. (2011): “The Website as An Integrated Marketing Tool: An Exploratory Study of French Wine Producers", Journal of Small Business and Entrepreneurship, vol. 24 (1), pp. 17-28.

HAIR, J. F., ANDERSON, R. E., TATHAM, R. y BLACK, W. C. (1999): Multivariate Data Analysis. Ed. Prentice Hall, $5^{\text {a }}$ Edición revisada

HALL, C.M. (1996): "Wine Tourism in New Zealand", in Proceedings of Tourism Down Under II: A Tourism Research Conference. University of Otago.

HALL, J. y WINCHESTER, M. (2000): "Focus on Your Consumer through Segmentation", Australia and New Zealand Wine Industry Journal, vol. 15 (2), pp. 93-96.

HANSON, W. (2000): Principles of Internet Marketing . Cincinnati Ohio, Southwest College Publishing.

HASMIM, N.H., MURPHY, J. y LAW, R. (2007): “A Review of Hospitality Website Design Frameworks", in P. O’Connor, W. Hopken, U. Gretzel (Eds.), Information and Communication Technologies in Tourism, New York: Springer-Wien: pp. 219-229.

HO, J. (1997): Evaluating the World Wide Web: a Global Study of Commercial Sites, Journal of Computer-Mediated Communication, vol. 3 (1), en www.ascusc.org/jcmc/ vol3/issue1/ho.html.

HU, C., HAN, Y.T., JANG, S.S. y BAI, B. (2005): "E-Relational Characteristics on Hospitality and Tourism Program Web Sites", Journal of Hospitality y Tourism Research, vol. 29 (4), pp. 508-522.

IAIA, L. SCORRANO, P., FAIT, M. y CAVALLO, F. (2017): "Wine, family businesses and web: marketing strategies to compete effectively", British Food Journal, vol. 119 (11), pp. 2.294-2.308.

JANKULOVIC, A., STAMATOVIC, M. y COVIC, D. (2013): "Website Data as Source for Strategic Decisions: the Case Study of Winery Websites", en Proceedings of International May Conference on Strategic Management, 24-26 may, Bor (Serbia), pp. 448-455.

JOHNSTON, D.A., WADE, M. y MCCLEAN, R. (2007):” Does e-Business Matter to SMEs? A Comparison of the Financial Impacts of Intemet Business Solutions on European and NorthAmerican SMEs", Journal of Small Business Management, vol. 45 (3), pp. 354-361.

KIM, I. y KULJIS, J. (2010): “Applying Content Analysis to Web-based Content”, Journal of Computing and Information Technology, vol. 18 (4), pp. 369-375.

KIM, D.J., KIM, W.G. y HAN, J.S. (2007): “A Perceptual Mapping of Online Travel Agencies and Preference Attributes”, Tourism Management, 28 (2), pp. 591-603

KIM, Y.H., YUAN, J., GOH, B.K. y ANTUN, J.M. (2009): "Web Marketingin Food Tourism: A Content Analysis of Web Sites in West Texas", Journal of Culinary Science y Technology, vol. 7 (1), pp. 52-64.

KRIPPENDORFF, K (2012): Content Analysis: An Introduction to Its Methodology. London, Sage Publications. 
LAW, R., QI, S. y BUHALIS, D. (2010): "Progress in Tourism Management: a Review of Websites Evaluation in Tourism Research", Tourism Management, vol. 31 (3), pp. 297-313.

LYNCH, P. y HORTON, S. (2002): Web Style Guide: Basic Design Principles for Creating Websites, Yale University, New Haven, CT.

MARZO-NAVARRO, M. y PEDRAJA-IGLESIAS, M. (2009): Wine Tourism Development from the Perspective of the Potential Tourist in Spain, International Journal of Contemporary Hospitality Management, vol. 21 (7), pp. 816-835.

MARZO-NAVARRO, M. y PEDRAJA-IGLESIAS, M. (2012): Critical factors of wine tourism: incentives and barriers from the potential tourist's perspective, International Journal of Contemporary Hospitality Management, vol. 24 (2), pp. 312-334.

MATELLANES, M. (2014): "Social media en el sector del enoturismo", Revista de Comunicación de la SEECI, Julio, año XVII (34), pp. 34-49.

MCDONALD, W.J. (1994): “Time Use in Shopping: The Role of Personal Characteristics", Journal of Retailing, vol. 70 (4), pp. 345-365.

MESSINGER, P.R. y NARASIMHAN, C. (1997): “A Model of Retail Formats Based on Consumers' Economizing on Shopping Time”, Marketing Science, vol. 16 (1), pp. $1-23$.

MITCHELL, R. y HALL, M.C. (2004): “The Post-Visit Consumer Behavior of New Zealand Winery Visitors", Journal of Wine Research, vol. 15 (1), pp. 39-49.

MILLS, J.A., PITT, L. y SATTARI, S. (2012): "Reading between the Vines: Analyzing the Readability of Consumer Brand Wine Websites", International Journal of Wine Business Research, vol. 24 (3), pp. 169-182.

MUELLER, S., OSIDACZ, P., FRANCIS, I.L. y LOCKSHIN, L. (2010): “Combining discrete choice and informed sensory testing in a two-stage process can it predict wine market share?", Food Quality and Preference, vol. 21 (7), pp.741-754.

MURPHY, J., RAFFA, L. y MIZERSKI, R. (2003): “The Use of Domain Names by E-Branding by the World's Top Brands", Electronic Markets, vol. 13 (3), pp. 30-40.

MURPHY, J., HO, P. y CHAN, C. (2005): "Competitive Analyses for Marketing Electronic Wine Tourism”, International Journal of Wine Business Research, vol. 17 (3), pp. 39-55.

NESS, L. (2006): “Creating Effective Winery Web Sites: Is Yours Worthy?”, Wines y Vines, June: pp. 84-89.

NIELSEN, J. (2000): Designing Web Usability. Indianapolis, New Riders Publishing.

NIELSEN, J. (2002): Top Ten Web-Design Mistakes of 2002, en http://www.useit.com/ alertbox/20021223.html

NOTTA, O. y VLACHVEI, A. (2013): “Web Site Utilization in SME Business Strategy: the Case of Greek Wine SMEs", en Proceedings of the $6^{\text {th }}$ International business and social Sciences Research Conference, 3-4 January, Dubai.

NOWAK, L.I. y NEWTON, S.K. (2008): "Using Winery Web Sites to Launch Relationships with Millennials", International Journal of Wine Business Research, vol. 20 (1), pp. 3-67. 
O10MEDIA (2017): "Vinos y Bodegas en Aragón", Observatorio de Posicionamiento en Google para Aragón, disponible en https:/www.o10media.es/blog/wp-content/ uploads/2017/03/estudio-vinos-aragon-google.pdf.

OBSERVATORIO ESPAÑOL DEL MERCADO DEL VINO (2018): Dossier Estadístico del Vino, en https://www.oemv.es/evento/dossier-estadistico-del-vino-10-aniversariodel-oemv.

O'NEILL, M., PALMER, A. y CHARTERS, S. (2002): "Wine Production as a Service Experience: The Effect of Service Quality on Sales", Journal of Services Marketing, vol. 16 (4), pp. 342-362.

PEDRAJA-IGLESIAS, M. y MARZO-NAVARRO, M. (2014): "Desarrollo del enoturismo desde la perspectiva de las bodegas familiares", Cuadernos de Turismo, $\mathrm{n}^{\circ} 34$, pp. 233-249.

QUINTON, S. y HARRIDGE-MARCH, S. (2006): “The Interaction of Technology in Entrepreneurial Marketing: An Illustrative Case from a Wine Merchant", Strategic Change, vol. 15 (2), pp. 85-102.

RAO, S.S., METTS, G. y MORA, C.A. (2003): "Electronic Commerce Development in Small and Medium Sized Enterprises: A Stage Model and Its Implications", Business Process Management Journal, vol. 9 (1), pp. 11-32.

RAW (2018): Comportamiento digital de las bodegas en España, en https://www.agenciaraw.com/lab/bodegas/, elaborado por la Agencia Raw de Marketing Digital.

SALLEHA, S., HASHIMA, N.H. y MURPHYA, J. (2015): "Instagram Marketing: A Content Analysis of Top Malaysian Restaurant Brands", E-Review of Tourism Research, vol.6, pp. 1-5.

SCHEGG, R., STEINER, T., FREY, S. y MURPHY, J. (2002): "Benchmarks of Web Site Design and Marketing by Swiss Hotels", Information Technology y Tourism, vol. 5 (2), pp. 73-89.

SELLITTO, C. (2005): "A Study of Emerging Tourism Features Associated with Australian Winery Websites", Information Technology y Tourism, vol. 7 (3-4), pp. 157-170.

SELLITTO, C. y MARTIN, B. (2003): "Internet Web-Site Adoption: A Study of 107 Victorian SME Wineries", en http://ausweb.scu.edu.au/aw03/papers/sellitto/paper.html

SELLITTO, C. y MCKENZIE, M. (2005): "Marketing Features of Small Winery Websites: Best Practices of Early Internet Adopting Australian Wineries", en Proceedings of the 2nd International Wine Marketing Symposium, Sonoma University, July 8-9.

SELLITO, C., WENN, A. y BURGESS, S. (2003): "A Review of the Web Sites of Small Australian Wineries: Motivations, Goals and Success", Information Technology and Management, vol. 4 (2-3), pp. 215-232.

SIMEON, R. y SAYEED, L. (2011): "Examining the Online Wine Tourism Experience of California Wineries", International Journal of Online Marketing, vol. 1 (1), pp. 24-40.

SPARKES, A. y THOMAS, B. (2001): "The Use of the Internet as a Critical Success Factor for the Marketing of Welsh Agro-Food SMEs in the Twenty-First Century", British Food Journal, vol. 103 (5), pp. 331-347.

STEVENS, N. y BURNS, E. (2005): "Website Use in the Hawke's Bay Wine Region of New Zealand", International Journal of Wine Marketing, vol. 17 (1), pp. 69-85. 
STRICKER, S., MUELLER, R. y SUMMER, D.A. (2007): “Marketing Wine on the Web”, Choices, 1 st Quarter, vol. 22 (1), pp. 31-34.

THACH, L. (2009): "Wine 2.0: The Next Phase of Wine Marketing? Exploring US Winery Adoption of Wine 2.0 Components", Journal of Wine Research, vol. 20 (2), pp. $143-57$.

TIMMERS, P. (2000): Electronic Commerce: Strategies and Models for Business-toBusiness Trading, Wiley, Qld.

TURBAN, E., MCLEAN, E., WETHERBE, J., BOLLOJU, N. y DAVISON, R. (2002): Information Technology Management: Transforming Business in the Digital Economy, 3rd edition. New York: John Wiley y Sons.

VELIKOVA, N., WILCOX, J. y DODD, T.H. (2011): "Designing Effective Winery Websites: Marketing-Oriented versus Wine-Oriented Websites", en Proceedings of the $6^{\text {th }}$ AWBR International Conference, Bordeaux Management Scholl, BEM (France), 9-10 June.

WANG, F., HEAD, M. y ARCHER, N. (2000): "A Relationship Building Model for the Web Retail Marketplace. Internet Research", Electronic Networking Applications and Policy, vol. 10 (5), pp. 374-384.

YUAN, J., MORRISON, A.M., LINTON, S., FENG, R. y JEON, S.-M. (2004): "Marketing Small Wineries: An Exploratory Approach to Website Evaluation", Tourism Recreation Research, vol. 29 (3), pp. 15-25.

ZHU, Y., BASIL, D.Z. y GORDON, M. (2009): "The Extended Website stage model: A Study of Canadian Winery Websites", Canadian Journal of Administrative Sciences, vol. 26 (4), pp. 286-300. 
